Beyond the Mean:

Understanding Firm-Level Consequences of Variability in Diversity Climate Perceptions

Max Reinwald

University of Konstanz

Hendrik Huettermann

University of St. Gallen

Heike Bruch

University of St. Gallen

Author Note

Max Reinwald, Graduate School of Decision Sciences, University of Konstanz, Konstanz, Germany; Hendrik Huettermann, Institute for Leadership and Human Resource Management, University of St.Gallen, St.Gallen, Switzerland; Heike Bruch, Institute for Leadership and Human Resource Management, University of St.Gallen, St.Gallen, Switzerland.

This research was supported by a PhD scholarship from the Graduate School of Decision Sciences at the University of Konstanz awarded to the first author.

Correspondence concerning this article should be addressed to Max Reinwald, Graduate School of Decision Sciences, University of Konstanz, P. O. Box D87, 78457 Konstanz, Germany. E-mail: max.reinwald@uni-konstanz.de

This article has been accepted for publication and undergone full peer review but has not been through the copyediting, typesetting, pagination and proofreading process which may lead to differences between this version and the Version of Record. Please cite this article as doi: 10.1002/job. 2344 
Beyond the Mean:

Understanding Firm-Level Consequences of Variability in Diversity Climate Perceptions

Keywords: workforce diversity, diversity climate, climate strength, affect, company performance 


\begin{abstract}
We develop and test an organizational-level model of the consequences of diversity climate for company performance. Drawing from affective events theory and the organizational climate literature, we highlight the role of idiosyncrasies in employees' diversity climate perceptions. Specifically, we consider diversity climate strength (i.e., agreement in employees' climate perceptions) as a boundary condition of diversity climate's organizational-level effects and expect high climate strength to be particularly beneficial in demographically diverse organizations. Moreover, we introduce collective positive affect as an underlying mechanism of diversity climate's conditional effects on company performance. Hypotheses are tested in a study of 82 German small and medium-sized companies with 13,695 surveyed employees. Results show a moderated mediation relationship where diversity climate is only positively related to organizational performance (via collective positive affect) at relatively high diversity climate strength. While this finding holds for both demographically diverse and homogeneous organizations, post hoc analyses provide initial evidence that a strong climate only helps to realize the effects of diversity climate on collective positive affect when members of age- and gender-related demographic subgroups converge in their climate perceptions. Our study contributes to a better understanding of diversity climate as an effective lever for managing diversity.
\end{abstract}




\section{Beyond the Mean:}

Understanding Firm-Level Consequences of Variability in Diversity Climate Perceptions Diversity in the workplace has shown to act as a double-edged sword for organizational effectiveness (Jackson \& Joshi, 2011). Therefore, actively managing a heterogeneous workforce is indispensable for realizing diversity's positive potential and preventing possible negative effects (Guillaume, Dawson, Otaye-Ebede, Woods, \& West, 2017). One factor that is considered to play a key role in this regard is diversity climate, which generally refers to employees' perceptions about the extent to which an organization values diversity by utilizing fair diversityrelated practices and socially integrating all personnel (McKay, Avery, \& Morris, 2008).

Accordingly, diversity climate has sparked considerable scholarly interest in recent years (for reviews, see Dwertmann, Nishii, \& van Knippenberg, 2016; McKay \& Avery, 2015). While prior research has generally posited positive consequences of pro-diversity organizational climate, extant unit-level studies have partially yielded inconsistent findings concerning the potential of diversity climate to enhance organizational effectiveness. For example, while some analyses show positive relationships of diversity climate with team and company performance (e.g., Boehm, Dwertmann et al., 2014; Boehm, Kunze, \& Bruch, 2014), others do not find significant unconditional associations with unit-level effectiveness (e.g., Gonzalez \& DeNisi, 2009; McKay et al., 2008). Thus, further research is needed to uncover when and how the positive effects of diversity climate are most likely to be realized.

One possible explanation for the inconsistent pattern of prior findings is that extant unitlevel research has not considered the extent to which employees vary in their perceptions of diversity climate. That is, employees can substantially differ in their appraisal of how much their company actually values diversity (Kossek \& Zonia, 1993), leading McKay and Avery (2015, p. 225) to the conclusion that "this calls into question the appropriateness of aggregating 
everyone's perceptions into a single score for the entire unit." To illustrate the meaningfulness of variance in employee perceptions, consider two similar organizations which both have a moderate average level of diversity climate. Conventional wisdom based on prior unit-level research would suggest they are equally likely to profit from this moderate diversity climate. But what if in one company all employees agree in their perceptions of a moderate pro-diversity climate, whereas in the other, the moderate average climate level results from a mixture of high, moderate, and low climate perceptions? The extent to which employees agree in their climate perceptions very likely has an impact on how they collectively respond to diversity-related policies, practices, and procedures (Schneider, Ehrhart, \& Macey, 2013).

Our study addresses this gap in research by considering the degree of within-unit agreement between employees' climate perceptions — also referred to as "climate strength"—as a boundary condition of diversity climate's unit-level effects. Following Mischel's (1976) concept of situational strength, we expect that in those organizations where employees agree in their climate perceptions (i.e., where the climate is "strong" rather than "weak"), organizational members as a collective are more likely to positively respond to high levels of diversity climate. Moreover, we propose the moderating effect of diversity climate strength to be most pronounced in organizations with high levels of demographic diversity, where pro-diversity policies, practices, and procedures are most likely to benefit the diverse workforce.

Further adding to a comprehensive understanding of diversity climate's unit-level effects, we examine employees' affective reactions as an underlying mechanism translating the beneficial effects of diversity climate into organizational performance. Since most of extant research has examined direct effects of diversity climate, relatively little is known about the underlying processes through which it exerts its influence on organizational outcomes (McKay \& Avery, 2015). As both diversity research (Ashkanasy, Härtel, \& Daus, 2002) and climate models of 
organizational effectiveness (Cox, 1994; Kopelman, Brief, \& Guzzo, 1990) emphasize the particular relevance of employees' emotional reactions, we draw from affective events theory (AET; Weiss \& Cropanzano, 1996) and introduce employees' collective positive affect as a mediator of diversity climate's organizational-level effects.

In sum, our study illuminates when (i.e., depending on which boundary conditions) and how (i.e., through which theoretical mechanisms) the positive influence of diversity climate on organizational performance is likely to unfold (see Figure 1). Thereby, the study contributes to theory and research on diversity climate in three notable ways. First, by examining diversity climate strength, our analysis adopts a contingency view and suggests that both the mean-level and inter-individual differences in climate perceptions need to be considered for drawing valid conclusions about diversity climate's unit-level effects. Thus, our study integrates two streams of diversity climate research that have developed independently in the past (Dwertmann et al., 2016): On the one hand, research on the unit level which has mean-aggregated individual appraisals of diversity climate, however without considering within-unit variability in employees' climate perceptions. On the other hand, research on the individual level which has examined differences in employees' perceptions of diversity climate on their personal attitudes and behaviors, yet without considering the implications of these differences on unit-level outcomes.

Second, our study integrates the diversity climate literature and the emotions literature to come to grips with the effects of diversity climate on organizational outcomes. While prior studies have chiefly focused on direct effects of diversity climate, we respond to McKay and Avery's (2010; 2015) call for examining mediating processes. By focusing on employees' collective positive affect, we acknowledge the particular relevance that has been ascribed to employees' emotional reactions in the context of workplace diversity (Ashkanasy et al., 2002).

Third, our study extends prior research by assessing the implications of a general 
diversity-friendly climate for organizational performance (Avery \& McKay, 2010). While there is generally a paucity of studies examining organizational-level consequences of diversity climate, initial empirical evidence thus far only exists for age-specific diversity climate (Boehm, Kunze et al., 2014). Thus, our study puts not only the "business case for diversity climate" to test, but also answers calls in the work climate literature to link facet-specific organizational climates to global outcomes such as organizational performance (Kuenzi \& Schminke, 2009).

\section{------ Insert Figure 1 about here ------}

\section{Theory and Hypotheses}

In our study, we follow McKay et al.'s (2008) definition of diversity climate as employees' perceptions about the extent to which policies, practices, and procedures implicitly or explicitly communicate that valuing diversity and socially integrating all personnel is an organizational priority. We thus focus on what Dwertmann et al. (2016) call the "fairness and discrimination perspective" (efforts to ensure equal employment opportunity and absence of discrimination) as compared to the "synergy perspective" (efforts to create synergy from diversity) on diversity climate. While the fairness perspective is generally argued to be conceptually most evident on the organizational level (Dwertmann et al., 2016), it also aligns with AET as our guiding theoretical perspective.

With regard to the conceptualization of diversity climate, an important distinction has to be made for our analysis: While we refer to diversity climate level as the average level of employees' appraisal of diversity-related policies, practices, and procedures in their company, diversity climate strength describes the extent to which individuals agree in their perceptions of diversity climate. Based on the general notion of climate strength as the degree of within-unit agreement among work unit members' climate perceptions (Schneider et al., 2013), people working in the same organization may agree or differ in their perceptions of how much their 
company actually values diversity and provides equal opportunities to all employees. This agreement, or lack thereof, may significantly influence diversity climate's effectiveness in promoting positive organizational outcomes (González-Romá \& Peiró, 2014).

With regard to the influence of diversity climate level on organizational performance, underlying mechanisms of the relationship have remained largely unexplored (for an exception, see Boehm, Kunze et al., 2014). Rather, extant research has primarily referred to general climate models of organizational effectiveness for theorizing on the consequences of diversity climate (Cox, 1994; Kopelman et al., 1990). These models point to the key role of employees' affect for climate effects to unfold. In a similar vein, the relevance of employees' emotional reactions has been stressed in the context of workplace diversity (Ashkanasy et al., 2002). Therefore, we draw from AET and introduce employees' collective positive affect as an outcome of diversity climate level; moreover, we scrutinize diversity climate strength as a contingency of the relationship to account for the inconsistencies in diversity climate effects revealed by prior research.

\section{Diversity Climate Level and Collective Positive Affect}

Collective positive affect describes the shared experience of positive emotions among the members of an organization (Menges, Walter, Vogel, \& Bruch, 2011). Emotions have their origin in individuals, but they can converge both in small groups and large organizations through common experiences as well as processes of emotion sharing (Rimé, 2009). Accordingly, researchers have found considerable agreement in affect among members of small groups and entire organizations (Barsade, 2002; Knight, Menges, \& Bruch, 2018). Of note, collective positive affect in whole organizations constitutes a relatively stable emotional state that is rather unreactive to single acute stimuli (Knight et al., 2018).

Generally, AET suggests that positive work events trigger positive feelings among organizational members (Weiss \& Cropanzano, 1996). We posit that a diversity-friendly climate 
describes an environment where positive diversity-related work events prevail that cumulate to establish collective positive affect. The link between climate and work events is also pointed out by Zohar and Luria (2004, p. 322) who note that "events serve as climate indicators that can reveal the priority of key facets, which may differ from formal declarations concerning the same issues." In the context of high levels of diversity climate, collective positive emotions among employees are likely to emerge for mainly two reasons.

First, in companies with a pronounced pro-diversity climate, organizational policies and practices designed for demonstrating appreciation, support and development of a diverse workforce are likely to manifest in positive everyday workplace events. Examples can be the experience that trainings are granted to employees irrespective of their demographic background, or that rewards are based on individual performance rather than demographic group membership (Dwertmann et al., 2016). Such events serve as an overarching positive stimulus and send signals of recognition, fairness, and growth to members of a diverse workforce. These signals have been shown to trigger positive emotions among employees (Basch \& Fisher, 2000) and when they repeatedly occur, they cumulate to a relatively stable state of collective positive affect.

Second, a high level of diversity climate promotes respectful and cooperative social interactions among diverse organizational members. As corporate policies, procedures, and practices signal that an organization values the contributions of its diverse personnel and emphasizes their fair treatment and inclusion, the acceptance, valuation, and integration of diverse others are likely to become internalized norms serving as guiding principles for the behavior of most employees (Boehm, Dwertmann et al., 2014; Zohar, 2000). As a consequence, respectful and cooperative interactions among diverse organizational members are fostered. Such positive social interactions again constitute affective events causing pleasure, happiness, and affection among organizational members (Basch \& Fisher, 2000). 
Besides positive work events as an overarching stimulus, collective positive affect may further disseminate through secondary and tertiary emotion sharing (Rimé, 2009). Employees experiencing positive feelings caused by fair and inclusive diversity-related policies and practices feel the need to share their emotions with others in a process of secondary emotion sharing. As those others, in turn, are likely to further spread the emotions they caught through tertiary emotion sharing, the positive emotions ripple through the organization and provide employees with a good sense of how people in the company typically feel.

Thus far, we have followed prior unit-level research by considering only the average level of diversity climate in organizations and implicitly assuming homogeneity in employees' climate perceptions. Yet, as organizational members can significantly vary in their appraisal of the extent to which their company values diversity (Kossek \& Zonia, 1993), the consistency (i.e., strength) of employees' climate perceptions may determine when the positive impact of high levels of diversity climate on collective positive affect actually unfolds (McKay \& Avery, 2015).

\section{The Moderating Role of Diversity Climate Strength}

Differences in employee perceptions of diversity climate may emerge in particular from unclear policies, practices, and procedures and their inconsistent implementation within the organization (Zohar, 2000). With regard to diversity-related HR management for example, a central challenge is that treatment in one area (e.g., access to mentoring) is not independent from but has to be aligned with treatment in other areas (e.g., promotion; Gelfand, Nishii, Raver, \& Schneider, 2005). In this regard, Boehm, Kunze et al. (2014) point out the difficulty of designing conclusive age-inclusive HR practices with which companies might unintentionally discriminate against younger employees in their effort of fighting discrimination against stigmatized older employees. In addition, inconsistent implementation of diversity-related policies, practices, and procedures by leaders at the subunit level may cause disagreement in employees' diversity 
climate perceptions. Thereby, particularly line managers' own attitudes toward diversity may influence how they implement specific policies (Greer, Homan, De Hoogh, \& Den Hartog, 2012).

To account for the influence of idiosyncrasies in diversity climate perceptions, we consider the interaction between diversity climate level and strength. We argue that high levels of diversity climate contribute most to collective positive affect when the climate is also strong (i.e., when inter-individual climate perceptions among employees vary little). Strong situations are present when aspects of the situation lead people to perceive events in their environment in similar ways and induce uniform responses (Mischel, 1976). By contrast, in weak situations individuals experience higher levels of ambiguity regarding appropriate responses to certain events in their environment. In such situations, interpersonal differences will be most central for individual reactions, thus leading to higher variability in responses (Schneider et al., 2013).

In organizations where diversity climate is both high and strong, employees work in an environment that consistently signals inclusion and fairness to a diverse workforce. Such an environment is characterized by a series of positive diversity-related work events and thus acts as a strong common stimulus for positive emotions for all employees (Menges et al., 2011). These positive emotions are further disseminated through processes of secondary and tertiary emotion sharing, when employees validate their personal positive feelings in exchange with their coworkers (Rimé, 2009). As a result, a relatively high level of collective positive affect emerges where all employees are aware that people in their organization typically experience positive feelings at work. Similarly, when diversity climate is low and strong, consistently low collective positive affect is likely to develop. Here, the lack of fairness and integration leads to a lack of positive diversity-related work events and the likely presence of negative events, resulting in low positive affect which is further spread through processes of emotion sharing among employees.

In contrast, when there is a high average appraisal of diversity climate but employees 
nevertheless differ in their individual climate perceptions (i.e., when the climate is high but weak), the consistency in individuals' affective reactions is reduced, a pattern which might also occur when diversity climate is low and weak (González-Romá \& Peiró, 2014; Schneider et al., 2013). In companies where the mean diversity climate level includes both perceivers of low and high diversity climate, a mixture of positive events (signaling inclusion and fairness) and negative events (signaling exclusion and discrimination) is present. Research on negative asymmetry (Baumeister, Bratslavsky, Finkenauer, \& Vohs, 2001; Labianca \& Brass, 2006) suggests that in such situations, in particular negative events have a disproportionally strong effect and thus have the potential to impair the emergence of collectively shared positive emotions among employees. This observation is also in line with Weiss and Cropranzano's (1996) seminal writing on AET in which the authors acknowledge that "the body of work suggests that negative events produce stronger [...] subjective feelings of affect" (p. 32).

In such situations with inconsistent emotions, individuals are particularly likely to refer to others to figure out how they collectively feel (Barsade \& Knight, 2015). Thereby, the exchange with coworkers through secondary and tertiary emotion sharing results in the insight that a range of emotional responses to diversity climate is present in the organization, with a disproportionally strong influence of negative events. As a consequence, the emergence of collectively shared positive affect among the employees of an organization is further diminished.

In sum, we expect a strengthening interaction effect (Gardner, Harris, Li, Kirkman, \& Mathieu, 2017) and propose that collective positive affect in organizations is more likely to benefit from diversity climate level as the organization's workforce shows increasing agreement in diversity climate perceptions.

Hypothesis 1: The relationship between diversity climate level and collective positive affect is moderated by diversity climate strength, such that the relationship is positive and 
strengthens as diversity climate strength increases.

\section{The Moderating Role of Demographic Diversity}

Further adding to a comprehensive understanding of the unit-level consequences of diversity climate, we propose the moderating effect of diversity climate strength to be most pronounced in organizations with high levels of demographic diversity. Demographic diversity generally pertains to surface-level attributes, such as age and gender (Harrison, Price, \& Bell, 1998). These attributes are likely to be highly salient and thus relevant for the effects of diversity climate to unfold as they are easily detectable and often used for stereotyping and discrimination (Heilman \& Eagly, 2008; Posthuma \& Campion, 2009).

In organizations with a demographically diverse workforce, employees are most likely to benefit from a high and strong diversity-friendly organizational climate. In such contexts, organizational members consistently perceive different demographic groups to be positively affected by diversity-related policies and procedures and encounter fair and inclusive treatment of demographically dissimilar coworkers in their everyday working life. As a consequence, a strong diversity-friendly climate will most frequently manifest in positive diversity-related work events and thus promote the emergence of collective positive affect. Put differently, in particular in the face of a diverse workforce, organizations can demonstrate their diversity-friendliness which manifests in positive diversity-related work events.

In addition, positive work events resulting from a strong diversity-friendly climate are particularly relevant for members of those demographic groups that are still underrepresented in many work contexts (Joshi \& Roh, 2009). Albeit diversity climate matters to members of all demographic groups (Boehm, Dwertmann et al., 2014), older employees and women are particularly likely to face stereotyping and discrimination in the workplace (Heilman \& Eagly, 2008; Posthuma \& Campion, 2009). Hence, they will be especially appreciative of diversity- 
friendly organizational policies, practices, and procedures and react with positive emotions to instances demonstrating organizational efforts to warrant fair treatment and equal opportunities (McKay, Avery, Liao, \& Morris, 2011). Such positive emotions again further spread through secondary and tertiary emotion sharing (Menges \& Kilduff, 2015). In contrast, a strong diversityfriendly climate is not likely to manifest as frequently in positive diversity-related work events in demographically homogeneous organizations. Accordingly, fewer positive emotional reactions and a less pronounced level of collective positive affect can be expected.

In the context of low diversity climate strength, the relationship between diversity climate level and collective positive affect is likely to be weaker when demographic diversity is high rather than low. In such situations, even small inconsistencies in diversity-related practices and procedures are likely to become visible as members of the demographically diverse workforce encounter frequent instances where diversity-related policies are not uniformly implemented. As a consequence, inconsistent diversity-related procedures produce more negative diversity-related work events which — due to their disproportionally strong effect—are particularly influential in collective emotion formation. Thus, diversity climate level's effect on collective positive affect is weakened. In contrast, when demographic diversity is low, a weak diversity climate does not carry as much weight. Here, inconsistent implementation of diversity-related practices is less likely to be interpreted as systematic unfair treatment of single demographic groups given the relative demographic homogeneity of the workforce. As a consequence, fewer negative diversityrelated work events emerge and the positive effect of diversity climate level on positive collective affect is more likely to be unaffected.

To conclude, we expect the enhancing moderating effect of diversity climate strength on the link between diversity climate level and collective positive affect to be more pronounced under higher demographic diversity in an organization. 
Hypothesis 2: The relationship between diversity climate level and collective positive affect is moderated by both diversity climate strength and demographic diversity (i.e., age and gender diversity), such that the enhancing interaction between diversity climate level and strength is more pronounced as demographic diversity increases.

\section{A Moderated Mediation Model of Diversity Climate and Organizational Performance}

Due to its influence on collective positive affect, we expect the conditional effect of diversity climate level to furthermore expand on organizational performance (Hmieleski, Cole, \& Baron, 2012; Menges et al., 2011).

High collective positive affect among employees most likely enhances organizational performance. As broaden-and-build theory (Fredrickson, 2003) suggests, positive emotions like enthusiasm or excitement help to broaden employees' awareness and promote the development of new ideas, behaviors, and social relationships. These novel thoughts, actions, and social ties allow individuals to draw on a wider range of behaviors that benefit work performance. For example, positive affect broadens individuals' cognition and allows them to engage in more complex logical reasoning and problem solving because it signals that they are currently in a safe situation (Schwarz \& Clore, 2003). Moreover, positive affect has been shown to engender high task persistence because individuals are said to be more optimistic about success on their tasks (Tsai, Chen, \& Liu, 2007). In a similar vein, individuals with positive affect have proved to be more cooperative and supportive in interactions with coworkers due to their tendency to recall positive memories of past interactions (Barsade, 2002; Tsai et al., 2007).

Due to the shared nature of collective positive affect, the beneficial effects described above are likely to unfold beyond the individual level. As prior collective-level research has pointed out, repeated interactions and interdependence among organizational members create shared norms of behavior or "routines" that are consistent with collective attitudes and affect 
(Morgeson \& Hofmann, 1999). Hence, it can be expected that collective positive affect creates an environment in which performance-enabling behaviors (e.g., increased task persistence, cooperation, and support) become a shared organizational norm (Menges et al., 2011). As a result, the range of behaviors in the work context that are observable and considered appropriate by the workforce is narrowed (Barrick, Thurgood, Smith, \& Courtright, 2015). For instance, in situations that are not governed by formal organizational rules, employees might still act in a way that benefits the organization; that is, their behaviors are marked by shared norms of cooperation, support, persistency and creative thinking.

Based on the foregoing arguments, we propose that collective positive affect constitutes a mediator of the relationship between diversity climate level and firm performance; moreover, we expect this indirect relationship to be contingent on both the sharedness of employees' diversity climate perceptions and the demographic composition of the workforce. Thereby, our assumption generally concurs with climate models of organizational effectiveness (Cox, 1994; Kopelman et al., 1990) and AET (Weiss \& Cropanzano, 1996) which emphasize the key role of employees' affective states for realizing positive effects on organizational performance. At the same time, we take a more nuanced perspective by examining both diversity climate strength and demographic diversity as critical boundary conditions of diversity climate's strengthening effects on collective positive affect and organizational performance.

Hypothesis 3: Diversity climate strength moderates the indirect relationship between diversity climate level and organizational performance, as mediated by collective positive affect. The indirect relationship is positive and strengthens as diversity climate strength increases.

Hypothesis 4: Diversity climate strength and demographic diversity both moderate the indirect relationship between diversity climate level and organizational performance, as mediated by collective positive affect. The indirect relationship is positive and strengthens as both diversity 
climate strength and demographic diversity increase.

\section{Methods}

\section{Data Collection and Sample}

We collected data as part of a larger project from German small and medium-sized enterprises (SMEs) in cooperation with a benchmarking agency. SMEs are a highly relevant study context as they account for the majority of companies worldwide, making up more than $99 \%$ of all enterprises in Germany that employ over $60 \%$ of the working population (Soellner, 2014). To be eligible for participation, companies could not have more than 5,000 employees and had to be located in Germany (Welter et al., 2014). Overall, 82 organizations participated in our study which had on average 380.99 employees $(S D=577.14)$ and belonged to four industries: service $(40.48 \%)$, manufacturing (34.52\%), trade (20.24\%), and finance (4.76\%). Overall 13,695 employees participated in all companies, leading to an average within-organization response rate of $68.54 \%$ ( $S D=27.02)$. Participating employees were mostly male (56.68\%), on average 38.69 years old $(S D=4.07)$, and had stayed with their company on average for 7.82 years $(S D=3.92)$.

To prevent possible concerns associated with common source bias, data were collected from four different sources, namely three unique groups of employees and the top HR executive in each company. To collect employee data, all employees were sent a standardized email invitation that outlined the study's purpose and contained a link to a web survey. We used a splitsample design (Rousseau, 1985) and randomly assigned employees to one of four different survey versions based on an algorithm programmed into the survey website. In our study, we used only those three survey versions that contained the items of interest for our model (in the following referred to as "version A-C"). To test if random assignment to questionnaire versions worked as intended, we checked for potential differences with respect to participants' age, gender, and job type. For this purpose, we specified regression models with the individual-level 
attributes as dependent variables and the questionnaire versions as dummy variables. We used a standard OLS model for age differences and found a non-significant overall model-fit $(F=.46$, $p=.63$ ). For gender (job type) differences, we used a (multinomial) logit model and also obtained non-significant overall model fits (gender: $\chi_{2}^{2}=.26, p=.89$; job type: $\chi^{2}{ }_{4}=3.38, p=.50$ ). These results indicate that random assignment to the different survey versions worked as expected.

Information about demographics (i.e., age and gender) was collected from all respondents. Survey Version A captured the items for diversity climate and centralization (control variable). Version $B$ assessed collective positive affect and version $C$ contained items to assess coworker support as another control variable. The top HR executive in each company provided information on the company's performance as well as several control variables. These top HR executives were predominantly male $(57.0 \%)$, averaged 45.64 years of age (SD=9.49), and had an average organizational tenure of 12.79 years $(\mathrm{SD}=10.95)$.

\section{Measures}

Unless stated otherwise, we used 5-point scales (from 1=strongly disagree to 5=strongly agree) for our measures (see Appendix for an overview). To justify aggregation of individual responses to the organizational level, we followed the advice of LeBreton and Senter (2008) and tested for both inter-rater agreement and inter-rater reliability using the average deviation index around the median $\left(\mathrm{AD}_{\mathrm{Md}(\mathrm{J})}\right.$; Burke, Finkelstein, \& Dusig, 1999), the median $r_{\mathrm{wg}(\mathrm{j})}$ index based on different distributions (James, Demaree, \& Wolf, 1984), and intraclass correlation coefficients ( $\mathrm{ICC}_{1}$ and $\mathrm{ICC}_{2}$; Bliese, 2000). For interpretation of the aggregation statistics, we relied on cutoff points commonly discussed in the literature (Bliese, 2000; LeBreton \& Senter, 2008). ${ }^{1}$

\footnotetext{
${ }^{1}$ For the $\mathrm{AD}_{\mathrm{Md}(\mathrm{J})}$ index, the cutoff point hinges on the number of response options for the Likert-type item. For 5-point scales, the $\mathrm{AD}_{\mathrm{Md}(\mathrm{J})}$ should be 0.8 or lower and for 7-point scales 1.2 or lower. A median $\mathrm{r}_{\mathrm{wg}}$ index between .31 and .50 can be judged as weak agreement, between .51 and .70 as moderate agreement, and between .71 and .90 as strong agreement. For the interpretation of $\mathrm{ICC}_{1}$, a value of .01 can be considered as weak, of .10 as
} 
Diversity climate level. Diversity climate level was captured in employee survey version A with McKay et al.'s (2008) four-item scale, with each item rated on a seven-point Likert scale. We found acceptable intra-class coefficients $\left(\mathrm{ICC}_{1}=.14, \mathrm{~F}=7.97, p^{<.001 ;} \mathrm{ICC}_{2}=.87\right)$. The median $\mathrm{AD}_{\mathrm{Md}(\mathrm{J})}$ index $\left(\mathrm{AD}_{\mathrm{Md}(\mathrm{J})}=.96\right)$ as well as the median $r_{\mathrm{wg}}$ index using a uniform $\left(r_{\mathrm{wg}(\mathrm{uniform})}=.83\right)$ and a slightly skewed distribution $\left(r_{\mathrm{wg}(\text { slightly skewed })}=.71\right)$ indicated strong inter-rater agreement. Yet, under a moderately skewed distribution, the value dropped to $r_{\mathrm{wg}(\text { moderately skewed) }}=.43$, indicating weak agreement (LeBreton and Senter, (2008). This indicates that under some response patterns, considerable within-unit variance in diversity climate perceptions might exist which further underlines the relevance of considering diversity climate strength along with its overall meanlevel. All items were averaged $(\alpha=.97)$ and responses were aggregated for every organization by taking the mean of individual diversity climate ratings.

Diversity climate strength. For measuring diversity climate strength, we used the same four items by McKay et al. (2008) as for diversity climate level. However, diversity climate strength was operationalized as within-organization agreement in individual diversity climate perceptions. Following prior climate research (e.g., González-Romá, Fortes-Ferreira, \& Peiró, 2009), we captured within-unit agreement with the $\mathrm{AD}_{\mathrm{M}(\mathrm{J})}$ index around the mean. We chose the $\mathrm{AD}_{\mathrm{M}(\mathrm{J})}$ index instead of other available strength measures, in particular the $r_{\mathrm{wg}(\mathrm{j})}$ index and the standard deviation $(S D)$, because recent literature drew attention to theoretical and practical advantages of the $\mathrm{AD}_{\mathrm{M}(\mathrm{J})}$. Most notably, compared to $r_{\mathrm{wg}(\mathrm{j}) \text {, }}$, the $\mathrm{AD}_{\mathrm{M}(\mathrm{J})}$ does not require the definition of a null distribution representing random variance in responses and is less prone for overstating the degree of agreement (Burke et al., 1999; LeBreton \& Senter, 2008). Moreover, in comparison to $S D$, the $\mathrm{AD}_{\mathrm{M}(\mathrm{J})}$ as a strength measure is more easily interpretable in the metric of the original Likert scale (Dunlap, Burke, \& Smith-Crowe, 2003). Still, to test the robustness of 
our findings, we re-ran all our analyses using $S D$ as an alternative strength measure as not all scholars argue for the use of the $\mathrm{AD}_{\mathrm{M}(\mathrm{J})}$ over $S D$ (e.g., Roberson, Sturman, \& Simons, 2007); thereby, our analyses revealed an almost identical pattern of findings (see Results section). As the $\mathrm{AD}_{\mathrm{M}(\mathrm{J})}$ is a measure of within-unit variability, we multiplied the $\mathrm{AD}_{\mathrm{M}(\mathrm{J})}$ values by -1 to assure that higher values indicate more agreement/higher diversity climate strength.

Demographic diversity. Demographic diversity was assessed based on all respondents' self-reports of their age and gender. To calculate an organization's diversity with respect to gender and age, we followed Harrison and Klein (2007) and used the standard deviation to measure age diversity and Blau's index to obtain gender diversity scores.

Collective positive affect. Participants assigned to survey version B were asked to indicate how often employees in their organization felt the following positive affective states at work: enthusiastic, inspired, excited, energetic, and euphoric. These items, which have been used in prior research at the organizational level (e.g., Knight et al., 2018; Menges et al., 2011), were adapted from the job-related affective well-being scale (van Katwyk, Fox, Spector, \& Kelloway, 2000). Inter-rater agreement was strong to moderate $\left(\mathrm{AD}_{\mathrm{Md}(\mathrm{J})}=.59 ; r_{\mathrm{wg}(\mathrm{uniform})}=.90 ; r_{\mathrm{wg}(\operatorname{slightly}}\right.$ skewed)=.83; $\left.r_{\mathrm{wg}(\text { moderately skewed) }}=.62\right)$ and inter-rater reliability was also acceptable $\left(\mathrm{ICC}_{1}=.16\right.$, $\left.\mathrm{F}=9.19, \mathrm{p}<.001 ; \mathrm{ICC}_{2}=.89\right)$. Items were averaged $(\alpha=.97)$ and aggregated to the company level.

Company performance $(\boldsymbol{\alpha}=\mathbf{8 0})$. We relied on top HR executives' subjective assessments of organizational performance. Objective performance indicators were not available for the majority of companies in our sample as these are mostly privately owned SMEs that are not legally obliged to publish annual performance results. In accordance with prior research, we conceptualized company performance to comprise both organizational and operational aspects (Combs, Crook, \& Shook, 2005; Venkatraman \& Ramanujam, 1986). Thus, in addition to one 
item asking about the company's overall performance, we included one item for organizational performance (increase in market shared) and one for operational performance (business efficiency; for a similar approach, see e.g., De Jong, Kunze, \& Bruch, 2017).

We consider the use of subjective performance ratings to be appropriate in particular for the following reasons: First, the top HR executives can be viewed as knowledgeable key informants due to their leading position in the companies and their high average tenure $(>12$ years). Second, subjective performance ratings make it possible to rely on SMEs as a research context in which objective performance data is often not publicly reported. Third, subjective ratings allow for comparable performance assessments in multi-industry samples like ours where objective performance indicators may not be directly comparable between companies (Singh, Darwish, \& Potočnik, 2016). Fourth, in order to further validate our subjective performance measure, we collected publicly available performance data for as many of the SMEs in our sample as possible. To this end, we conducted a search in the database "Unternehmensregister" in which the German Federal Ministry of Justice and Consumer Protection compiles annual reports of privately owned firms. Thereby, we were able to obtain information on Return on Equity (ROE) for 31 of the 82 companies in the respective time period. Our three-item performance measure correlated significantly with the ROE of these companies $(r=.39, p=.04)$; moreover, the ROE was also significantly associated with collective positive affect $(r=.42 ; p<.01)$. These results lend further support to the validity of HR executives' subjective assessments in our full sample.

Controls. We considered several additional factors which might have influenced the variables in our model. First, we included company size (i.e., number of employees) to account for the potential influence on employee attitudes and performance (Pierce \& Gardner, 2004). Members of larger organizations have been argued to show lower levels of affect as they are more likely to become alienated from their work (Schminke, Cropanzano, \& Rupp, 2002). 
Moreover, larger companies may profit more from economies of scale and might be better able to attract and retain talented employees (Orlitzky, 2001). To reduce skewness of this variable, we log-transformed it. Second, we controlled for company age as older companies are more likely to have structured personnel practices with potential effects on employee affect (Knight et al., 2018) and firm performance due to increased profitability of foreign operations, technological learning, and sales growth (Zahra, Ireland, \& Hitt, 2000). Third, we considered staffing sufficiency by asking top HR executives to rate their company's current level of staffing in relation to the tasks that need to be done (Ganster \& Dwyer, 1995). Insufficient staffing might lead to fewer positive emotions (e.g., higher stress due to increased workload) and diminished performance (e.g., reduced goal attainment due to lack of human resources; Kunze, Raes, \& Bruch, 2015).

Fourth, we included slack resources as they may affect both a company's performance as well as its ability to reach organizational goals in terms of diversity management (George, 2005). To capture slack resources, we asked top HR executives to rate the firm's financial situation with respect to liquidity and the ability to set up financial reserves in the previous year on a seven point Likert scale. Fifth, we controlled for the degree of centralization as prior research has shown it to influence employees' affect and firm performance (Baum \& Wally, 2003; Walter \& Bruch, 2010). Centralization may increase employees' work alienation and decreases participation in decision-making, thereby leading to less positive emotions (Knight et al., 2018; Walter \& Bruch, 2010). Furthermore, it has the potential to increase an organization's strategic decision speed which in turn may foster firm performance (Baum \& Wally, 2003). We measured this variable with three items adapted from Hage and Aiken (1967) rated on a seven-point scale in survey version $\mathrm{A}\left(\alpha=.97 ; \mathrm{AD}_{\mathrm{Md}(\mathrm{J})}=1.20 ; r_{\mathrm{wg}(\text { uniform })}=.62 ; \mathrm{ICC}_{1}=.10, \mathrm{~F}=5.50, p<.001 ; \mathrm{ICC}_{2}=.82\right)$. Sixth, to increase the predictive validity of collective positive affect, we included the 
degree of coworker support as an indicator for the quality of social exchange relationships. Prior research has shown that social exchange processes may also account for the relationship between diversity climate level and outcomes (Boehm, Kunze et al., 2014). We measured this variable with two items from Jetten, Haslam, and Haslam (2012) in employee survey C ( $\alpha=.88$;

$\left.\mathrm{AD}_{\mathrm{Md}(\mathrm{J})}=.61 ; r_{\mathrm{wg}(\text { uniform })}=.76 ; \mathrm{ICC}_{1}=.07, \mathrm{~F}=4.08, p<.001 ; \mathrm{ICC}_{2}=.75\right)$. Finally, we controlled for industry affiliation, as employees' affect and company performance may systematically differ between industry sectors (Agarwal, Sarkar, \& Echambadi, 2002; Menges et al., 2011). In consumer centric industries (i.e., service) for example, the primary business objective is creating positive emotions and accordingly, those organizations tend to have generally higher positive affect among employees (Knight et al., 2018). Thus, we included three industry dummy variables (i.e., production, trade, service), using the finance sector as reference category.

\section{Convergent and Discriminant Validity}

To assure convergent and discriminant validity, we performed a series of confirmatory factor analyses (CFAs) at the organizational level. We relied on a combination of absolute (i.e., SRMR) and incremental fit indices (i.e., CFI, TLI) to assess model fit, as recommended for small sample sizes (Hu \& Bentler, 1999). We used common cutoff values discussed in the literature: .08 or lower for the SRMR (Hu \& Bentler, 1999) and above .90 for CFI and TLI (Marsh, Hau, \& Wen, 2004; Meyers, Gamst, \& Guarino, 2006). In addition, we used Akaike's information criterion (AIC) for model comparison, where better model solutions have smaller values.

We estimated a five factor CFA including the three focal study variables (diversity climate level, collective positive affect, and organizational performance) along with the two multi-item control variables centralization and coworker support. We allowed the latent factors to correlate freely, and neither specified error correlations between indicators nor cross-loadings. 
Our hypothesized five factor model showed an acceptable fit $\left(\chi_{109}^{2}=191.17\right.$; SRMR=.08;

$\mathrm{CFI}=.95 ; \mathrm{TLI}=.94 ; \mathrm{AIC}=682.46$ ). The hypothesized five factor model was then compared to four alternative models: One with diversity climate level and collective positive affect loading on a common factor $\left(\chi_{113}^{2}=477.72 ; \Delta \chi^{2}=286.56, p=.00 ; \mathrm{SRMR}=.12 ; \mathrm{CFI}=.78 ; \mathrm{TLI}=.74 ; \mathrm{AIC}=961.02\right)$, one with diversity climate level, collective positive affect, and coworker support as one factor $\left(\chi_{116}^{2}=506.67 ; \Delta \chi^{2}=315.50, p=.00 ; \mathrm{SRMR}=.12 ; \mathrm{CFI}=.76 ; \mathrm{TLI}=.72 ; \mathrm{AIC}=983.96\right)$, one with positive affect and performance as one factor $\left(\chi_{113}^{2}=261.15 ; \Delta \chi^{2}=69.99, p=.00 ; \mathrm{SRMR}=.08\right.$; $\mathrm{CFI}=.91 ; \mathrm{TLI}=.89 ; \mathrm{AIC}=744.45)$, one with positive affect, performance, and centralization as one factor $\left(\chi_{116}^{2}=548.18 ; \Delta \chi^{2}=357.01, p=.00 ; \mathrm{SRMR}=.13 ; \mathrm{CFI}=.74 ; \mathrm{TLI}=.69 ; \mathrm{AIC}=1025.48\right)$, and one with all variables loading on a single factor $\left(\chi^{2}{ }_{119}=775.95 ; \Delta \chi^{2}=584.79, p=.00 ; \mathrm{SRMR}=.12\right.$; $\mathrm{CFI}=.60 ; \mathrm{TLI}=.55 ; \mathrm{AIC}=1247.25)$. All alternative models fit the data significantly worse than our hypothesized model. $^{2}$

\section{Analytical Techniques}

Hypotheses were tested at the organizational level based on linear regressions with robust standard errors using the statistical software package Stata 14.2. For testing the moderation effects, variables were grand-mean centered prior to interaction to facilitate interpretation. For probing the interactions, we followed the recommendations by Gardner et al. (2017). Accordingly, we first followed the traditional "pick a point" approach and computed the simple slopes at "high" (1 SD above the mean) and "low" (1 SD below the mean) levels of the moderator. Then, we calculated exact regions of significance for the conditional effect (region of

\footnotetext{
${ }^{2}$ To rule out that small sample size-to-parameter ratios might bias the findings of our CFAs, we performed additional tests to establish discriminant validity by analyzing all possible pairs of the five constructs in a series of two-factor CFAs (Anderson \& Gerbing, 1988). Each two-factor CFA was run twice: Once with an unrestricted correlation between the two latent factors and once with the correlation between the factors restricted to 1 . A chisquare difference test was then performed between the two nested models; discriminant validity is present when the unrestricted model fits significantly better than the restricted model. For all possible pairs of constructs the unrestricted model fitted significantly better $(p<.001)$ than the restricted one, with chi-square differences between 39.46 and 327.44 .
} 
the moderator variable within which the relationship between predictor and criterion is significantly different from zero) using the Johnson-Neyman technique (Johnson \& Neyman, 1936). For analyzing conditional indirect effects, we followed the product-of-coefficient procedures proposed by Preacher, Rucker, and Hayes (2007). We obtained bootstrapped $(n=5,000)$ point estimates for the indirect effects between diversity climate level and organizational performance (through collective positive affect) at different values of the moderator using the probing procedures described above. To assess the level of significance of the estimates, we relied on bias-corrected $95 \%$ confidence intervals (BCCIs) to account for the skewed and kurtotic distribution of indirect effect estimates in finite samples (Preacher et al., 2007).

\section{Results}

\section{Descriptive Statistics and Intercorrelations}

Table 1 presents means, standard deviations, and intercorrelations of the study variables. In support of our model, collective positive affect is positively related to company performance $(r=.46 ; p=.00)$. In addition, a significant relationship between diversity climate level and company performance exists $(r=.42 ; p=.00)$.

The finding that diversity climate level and strength show a relatively high correlation $(r=.70)$ is not uncommon in studies involving strength measures, but increases the difficulty of detecting interaction effects (Cole, Bedeian, Hirschfeld, \& Vogel, 2011). In fact, high intercorrelations are only worrisome when they produce severe multicollinearity. Therefore, we tested for multicollinearity and all variance inflation factors (VIFs) fell well below the critical value of 10 (O'Brien, 2007). The mean VIF was $2.11(\mathrm{SD}=.87)$ for the two-way moderation model, $2.82(\mathrm{SD}=1.28)$ for the three-way interaction with age diversity, and $2.20(\mathrm{SD}=.82)$ for the three-way interaction with gender diversity. In a similar vein, the highest condition index was 
5.07 for the two-way interaction model and 6.61 and 5.27, respectively, for the three-way interaction models, which is far below the cut-off value of 30 (Tabachnick \& Fidell, 2013).

Insert Table 1 about here ------

\section{Hypothesis Testing}

Hypothesis 1 predicts diversity climate strength to moderate the relationship between diversity climate level and collective positive affect. As shown in Table 2 (step 3), the interaction term turns out to be significant $(B=.27 ; p=.04)$. To further inspect whether the pattern of the interaction is in line with our prediction in Hypothesis 1 (i.e., that the relationship between diversity climate level and collective positive affect is positive and strengthens as diversity climate strength increases), we first calculated simple slopes at "high" (+1 SD: $B=.26 ; p=.01)$ and "low" (-1 SD: $B=.13 ; p=.26)$ levels of the moderator. Results suggest that the effect of diversity climate level on collective positive affect only exists in organizations with relatively high diversity climate strength.

We further probed the boundaries of the moderation effect with the Johnson-Neyman technique using the $95 \%$ region of significance. In our case, the relationship between diversity climate level and collective positive affect is positive and significant only for mean-centered diversity climate strength values of $.01(B=.20)$ or above, and reaches conditional effects up to $B=$ .38 for the maximum observed diversity climate strength value in the data (mean-centered diversity climate strength Max $=.69$ ). For diversity climate strength values smaller than .01 , the relationship between diversity climate level and collective positive affect is not significant within the range of observed diversity climate strength values. The lower bound where the slope parameter becomes significantly negative falls well outside of plausible data values, with a lower bound value for mean-centered diversity climate strength of -50.83 , whilst the lowest observed diversity climate strength value is -.78. In our sample of 82 organizations, $33(40.24 \%)$ have a 
diversity climate strength value above .01 and thus exhibit a positive conditional relationship between diversity climate level and collective positive affect, whereas 49 organizations (59.76\%) have values lower than .01 and therefore exhibit a non-significant conditional relationship. The interaction pattern based on the Johnson-Neyman technique is illustrated in Figure 2.

Taken together, these analyses provide support for the strengthening effect proposed in Hypothesis 1, as the relationship between diversity climate level and collective positive affect is positive and stronger with increasing diversity climate strength, but is never significantly negative in the range of our study.

\section{----- Insert Table 2 about here ------ \\ Insert Figure 2 about here ------}

In Hypothesis 2, we postulate a three-way interaction between diversity climate level, diversity climate strength and demographic diversity (i.e., age and gender diversity), such that the interaction between diversity climate level and diversity climate strength is stronger when demographic diversity increases. As can be seen from Table 2, neither the three-way interaction with age diversity $(B=-.05 ; p=.34)$ in step 4 nor the three-way interaction with gender diversity in step $5(B=.93 ; p=.45)$ is significant. Thus, Hypothesis 2 is not supported.

Hypothesis 3 suggests a moderated mediation relationship, whereby the indirect association between diversity climate level and organizational performance, mediated by collective positive affect, is positive and strengthens with increasing diversity climate strength. Thus, we first inspected whether collective positive affect is positively associated with company performance. As can be seen in Table 3 (step 3), collective positive affect has a significant positive relationship with performance $(B=.82 ; \mathrm{p}=.00)$. Next, we directly tested the conditional indirect effect. At relatively high values of diversity climate strength $(+1 S D)$, diversity climate level has a positive indirect association with firm performance (indirect point estimate $B=.22$; 
BootSE=.11; BCCI[.052, .542]), while the indirect relationship is not significantly different from zero at relatively low (-1 SD) diversity climate strength (indirect point estimate $B=.11$;

BootSE=.12; BCCI[-.050, .441]). In terms of the Johnson-Neyman technique, the upper bound value of mean-centered diversity climate strength (i.e., the value beyond which the conditional indirect effect becomes statistically significant) is -.07 (indirect point estimate $B=.15$;

BootSE=.11; BCCI[.000, .478]). The value of the indirect point estimate increases up to $B=.31$ (BootSE=.15; BCCI[.094, .713]) for the maximum mean-centered value of diversity climate strength observed in the data (diversity climate strength ${ }_{\text {Max }}=.69$ ). For the lowest observed diversity climate strength score in our data (diversity climate strength ${ }_{\text {Min }}=-.78$ ), the indirect effect is negative but far from being statistically significant (indirect point estimate $B=-.01$;

BootSE=.16; BCCI[-.307, .352]). Thus, the diversity climate level-firm performance relationship does not become significantly negative in the range of observed sample values. These results provide support for the strengthening indirect effect of diversity climate level on organizational performance under increasing values of diversity climate strength proposed in Hypothesis 3. Insert Table 3 about here ------

Finally, Hypothesis 4 suggests a moderated mediation relationship where diversity climate strength and demographic diversity both moderate the indirect relationship between diversity climate level, collective positive affect, and organizational performance. However, as the results for Hypothesis 2 indicate no significant three-way interactions between diversity climate level, diversity climate strength, as well as age and gender diversity, a necessary precondition for the conditional indirect effects is not met. Thus, Hypothesis 4 is not supported.

To further evaluate the robustness of our findings, we conducted several additional analyses. First, following the advice of Cole et al. (2011), we tested for curvilinear effects of both diversity climate level and strength as a rival explanation for the observed two-way interaction 
effect between diversity climate level and diversity climate strength. We entered squared terms of diversity climate level and strength as predictors in a regression model, but both squared terms did not reach conventional levels of significance. Second, we tested an alternative measure to operationalize diversity climate strength as some authors have drawn on the sign-reversed $S D$. A re-estimation of the two-way moderation effect of diversity climate strength based on the signreversed $S D$ revealed a significant effect $(B=.27 ; p=.04)$, similar to the results for $\mathrm{AD}_{\mathrm{Md}(\mathrm{J})}$ as a strength measure; moreover, also the two three-way interactions involving either age or gender diversity remained non-significant when using the sign-reversed $S D$ as a strength measure. Third, we re-ran our regression models and included affect dispersion as either a control variable or as a moderator when studying the effect of collective positive affect on company performance. We operationalized affect dispersion similar to our measure of climate strength as the average deviation index around the mean $\left(\mathrm{AD}_{\mathrm{M}(\mathrm{J})}\right)$. All our results remained nearly identical and no main conclusion was altered. Fourth, following Becker (2005), we re-ran all hypothesis tests without control variables. The pattern of results remained unchanged in all analyses.

\section{Post hoc Analyses}

Contrary to expectations, the three-way interactions between diversity climate level, diversity climate strength and demographic diversity did not turn out to be significant. One possible explanation for this unexpected finding could be that rather than the demographic composition of the workforce, differences in diversity climate perceptions between demographic subgroups may determine whether a strong climate actually helps to realize the positive potential of diversity climate. Such variability in diversity climate perceptions along demographic subgroup boundaries would indicate a lack of fairness and valuation toward single demographic groups and thereby undermine the potential of diversity climate strength to positively moderate the effect of diversity climate level on collective positive affect. Subgroup differences in diversity 
climate perceptions may occur in particular when maximum diversity climate strength (i.e., perfect agreement in climate perceptions) is absent, a situation which applies to all organizations in our sample. In such cases, a moderate diversity climate strength where climate perceptions are unrelated to demographic subgroup membership may be substantially different from a diversity climate with similar moderate strength where however single demographic subgroups perceive the climate to be systematically less diversity-friendly than others.

A systematic lack of fairness toward single demographic subgroups would furthermore create a situation where differences between subgroups are particularly pronounced (Hogg \& Terry, 2000). As a consequence, social identity processes are likely to emerge which have been shown to promote conflict and impede cooperation and communication between demographic subgroups (van Knippenberg \& Schippers, 2007). Hence, less positive work events and more negative work experiences are likely to occur, thereby reducing the impact of diversity climate strength on the link between diversity climate level and collective positive affect. Accordingly, we performed post hoc tests to check if the two-way interaction between diversity climate level and diversity climate strength is more pronounced when the average diversity climate perceptions converge between demographic subgroups.

To this end, we calculated the average climate perceptions for both age- and genderrelated demographic subgroups in each organization. With regard to gender, we calculated the perceived diversity climate for women and men; to determine convergence, we calculated absolute differences between male and female climate perceptions. To assure that higher levels mean higher convergence, we multiplied the difference score by minus 1 . Concerning age-related differences in diversity climate perceptions, we calculated the absolute sign-reversed differences between older and younger employees. Following $\mathrm{Ng}$ and Feldman (2008), we distinguished between workers younger and older than 40 years as the age of 40 is often used to refer to older 
workers from a legal standpoint. For example in the US, the Age Discrimination in Employment Act of 1967 prohibits employment discrimination against anyone older than 40 years. Similar legislative initiatives exist in Germany, where court rulings abolished the maximum entry age of 40 for specific jobs (e.g., stewardesses, non-tenured professorships). Accordingly, we expect the 40 years cutoff to be particularly salient in the organizations under study.

To test our theoretical rationale, we considered the same set of control variables plus age and gender diversity along with two three-way interactions including diversity climate level, diversity climate strength, and convergence in diversity climate perceptions either between younger and older employees or between men and women. As can be seen from Table 4, the three-way-interaction involving age-related convergence in diversity climate perceptions is significantly related to collective positive affect $(B=.75 ; p=.01)$. As there is, to the best of our knowledge, currently no straightforward approach that allows for fully capitalizing on the advantages of the Johnson-Neyman technique for three-way interactions (Dawson \& Richter, 2006), we only report results of simple slope analyses in the following. ${ }^{3}$ As can be seen in the left panel of Figure 3, we plotted the interaction effect for high and low values of the moderator $(+1$ SD and -1 SD). Only when both diversity climate strength and age-related convergence in diversity climate perceptions are high, diversity climate level is positively related to collective positive affect $(B=.46 ; p=.01)$. For all other combinations of diversity climate strength and agerelated convergence in diversity climate perceptions, the effect of diversity climate level is not significantly different from zero ( $p$-values of .46 or higher). Additionally, slope difference tests indicate that the slope for high diversity climate strength and high age-related convergence in

\footnotetext{
${ }^{3}$ Specifically, there is no straightforward way for determining and parsimoniously reporting regions of significance for the entire range of values of two continuous moderating variables in three-way interactions. Rather, the standard procedure in such cases is to calculate regions of significance for two-way interactions at selected values (e.g., +1 and $-1 S D$ ) of the second moderator, thus again following a "pick a point" logic (Preacher, Curran, \& Bauer, 2006). Nonetheless, we re-ran our analysis following this approach and the pattern of results from the simple slope analyses was confirmed (results available from the authors upon request).
} 
diversity climate perceptions is significantly more positive than the slopes for all other combinations ( $p$-values of .01 or lower for difference tests).

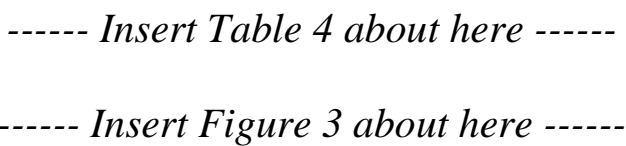

Similarly, the three-way interaction between diversity climate level, diversity climate strength, and gender-related convergence in diversity climate perceptions is significantly related to collective positive affect $(B=.71 ; p=.05)$. The pattern of the interaction is displayed in the right panel of Figure 3. In this case, the slope of diversity climate level is only positively related to collective positive affect when both diversity climate strength and gender-related convergence in diversity climate perceptions is high $(B=.28 ; p=.06)$. In contrast, under all other combinations of diversity climate strength and gender-related convergence in diversity climate perceptions, the slope is not significantly different from zero ( $p$-values of .70 or higher). The slope for high diversity climate strength and high gender-related convergence in diversity climate perceptions is only significantly different from the slope with low diversity climate strength and high genderrelated convergence in diversity climate perceptions $(t=2.11 ; p=.04)$, but not from all other slopes.

In sum, these findings provide initial evidence that collective positive affect is only promoted by diversity climate level when the climate is strong and at the same time, demographic subgroups agree in their climate perceptions. In contrast, in situations where either the climate is weak or agreement in climate perceptions between demographic subgroups is low or where both are low, collective positive affect does not profit from a high diversity climate level.

\section{Discussion}

Drawing from AET and the organizational climate literature, this study aimed at opening the "black box" between diversity climate and company performance. Our empirical analysis of 
82 companies with a total of 13,695 employees participating shows that the indirect relationship between diversity climate level and company performance through collective positive affect depends on diversity climate strength (i.e., inter-individual agreement in employees' diversity climate perceptions). Specifically, we find that the positive effects of high levels of diversity climate are only realized when the climate is also strong. Contrary to expectations, we do not find the moderating role of diversity climate strength to be more pronounced in demographically diverse organizations. Yet, our post hoc results provide initial evidence that a strong diversityfriendly climate only unfolds its positive impact when age- and gender-related demographic subgroups concur in their appraisal of the organization's diversity-friendliness.

\section{Theoretical Implications}

The results of our analysis contribute to extant theorizing and research on diversity climate in three major ways. First, our study helps to illuminate the inconsistent findings of prior research on the association between diversity climate and organizational effectiveness by considering boundary conditions of the relationship. Thereby, our analysis demonstrates the relevance of taking into account variability in individual employees' diversity climate perceptions (Dwertmann et al., 2016). Thus, our findings point future collective-level (i.e., organization- or team-based) research to the need to consider not only the average level of diversity climate, but also potential differences in climate perceptions for making valid conclusions about diversity climate's unit-level effects (McKay \& Avery, 2015).

Our analysis furthermore reveals that high diversity climate strength is equally relevant in both demographically (i.e., age and gender) diverse and homogeneous organizations. This pattern of findings resonates with the study by McKay et al. (2011) who found no difference in diversity climate effects between stores with high and low female representation. While the authors speculate that this result might indicate that fair and inclusive work environments are valued by 
all employees, our study provides an alternative explanation. Based on post hoc analyses, we find that the beneficial effects of diversity climate only hold for companies with low variability in diversity climate perceptions across demographic subgroups. That is, only when members of ageand gender-related subgroups equally perceive their company to value diversity, the positive impact of a high and strong diversity climate is realized. These results suggest that while low climate strength independent from demographic attributes may only lead to general uncertainty regarding the valuation of diversity in the organization, systematic differences in climate perceptions along demographic lines may actually be interpreted as clear signs of systematic unfairness toward specific demographic groups. As a consequence, the salience of demographic differences and social categorization processes may be triggered, thereby undermining the potential of diversity climate to stipulate collective positive affect (Hogg \& Terry, 2000). This finding adds a novel aspect to the diversity climate literature and indicates the need to further explore the implications of subgroup-specific patterns of diversity climate perceptions.

By considering the average level of diversity climate together with individual differences in climate perceptions, our study bridges the divide between individual-level (i.e., psychological) and collective-level diversity climate studies. Psychological diversity climate studies conceptualize climate as an individual-level construct and indicate that individual-level outcomes can be predicted by between-person variance in diversity climate perceptions (e.g., ChrobotMason \& Aramovich, 2013). In contrast, collective diversity climate studies conceive climate as a shared attribute of a group or organization and scrutinize between-unit (i.e., between-teams or between-organizations) variance for explaining unit-level outcomes (e.g., Gonzalez \& DeNisi, 2009). Psychological and collective diversity climate studies have developed largely independently from one another and our study is the first to echo the call for integrating both streams of research (Dwertmann et al., 2016). Thereby, we can show that both high average 
levels of diversity climate and homogeneity in individuals' climate perceptions are necessary for realizing the positive potential of diversity climate. In this regard, we also provide an answer to the question whether the effects of climate strength found for other facet-specific climates at the sub-organizational level generalize to the organizational level (González-Romá \& Peiró, 2014).

The second major contribution of our study concerns the role of shared positive affect as a collective-level mechanism translating the effects of diversity climate on organizational performance. While there is generally a paucity of research on mediators of diversity climate's organizational-level effects (McKay \& Avery, 2015), we focus on the key role of employee affect that has been proposed in both the diversity (Ashkanasy et al., 2002) and the organizational climate literature (Cox, 1994; Kopelman et al., 1990). By empirically proving the relevance of collective positive affect in organizations, we complement prior findings on age-specific diversity climate that have examined the role of social exchange processes in the relationship with organizational outcomes (i.e., Boehm, Kunze et al., 2014). Our findings support the notion that diversity climate can facilitate positive collective emotions, which in turn benefit the organization. That way, we also provide support for the idea recently posited by Parke and Seo (2017) that the beneficial effects of inclusive climates can be explained by affective reactions of the collective.

Our findings on the role of collective positive affect also contribute to research on emotions in organizations (see Menges \& Kilduff, 2015, for a review). While drivers of collective affect have been mostly studied in small groups, comparably little is known about organizationallevel antecedents (Barsade \& Knight, 2015; Knight et al., 2018). Our findings suggest that organizations can actively promote the emergence of collective positive affect by establishing unambiguous procedures, policies, and practices that signal fairness and inclusion to a diverse workforce. Future research could extend this route by looking at affective responses to other 
organizational-level factors, such as certain HR practices or CEO actions. Moreover, our results demonstrate that positive affect enhances company performance. This finding complements previous studies revealing beneficial effects on employee sick days (Knight et al., 2018), task performance behavior (Menges et al., 2011), and new venture growth (Hmieleski et al., 2012).

The third contribution of our study pertains to company performance as an organizationallevel outcome of a general diversity-friendly climate. Overall, the organizational-level performance consequences of diversity climate are relatively underexplored (Dwertmann et al., 2016; McKay \& Avery, 2015). Except for one company-level study on age-specific diversity climate (Boehm, Kunze et al., 2014), previous studies have focused on the team-, store-, and unitlevel when studying collective-level performance consequences of diversity climate. With our study, we find that the beneficial effects of a general (i.e., not attribute-specific) diversity climate previously found for organizational subunits are transferable to the company level. This finding provides an initial answer to the question raised by Avery and McKay (2010, p. 244) of whether "diversity climate serves as a source of competitive advantage between firms?". In addition, the link between diversity climate and firm performance contributes to climate research in general. As noted in climate reviews, links between facet-specific climates (e.g., diversity, service, innovation) and global company outcomes have the potential to draw more attention to climate as a strategic management tool (Kuenzi \& Schminke, 2009; Schneider et al., 2013).

\section{Managerial Implications}

Diversity climate level has shown to be most beneficial for organizational performance when employees' across different demographic subgroups agree in their climate perceptions. Therefore, we encourage practitioners to design and implement consistent diversity-friendly organizational policies, practices, and procedures that warrant fair and inclusive treatment of all employees. Previous work suggests in particular two, partly interrelated, ways of promoting 
diversity climate: diversity-friendly HR practices and high diversity at all organizational ranks (Herdman \& McMillan-Capehart, 2010). These measures are considered to send visible and salient signals to employees that the organization is committed to and values diversity (Boehm, Kunze et al., 2014). Yet, prior research also suggests that implementing these measures is often not enough, as signals sent by those practices might be interpreted differently, depending on the context in which they occur (e.g., diversity in community; Pugh, Dietz, Brief, \& Wiley, 2008) or by whom they are interpreted (e.g., rater's identity; McKay \& Avery, 2006). Thus, against the background of our findings, organizations should take special care in minimizing the ambiguity of diversity-related efforts and avoid unintended discrimination of specific demographic groups.

Our findings and the diversity climate literature suggest a couple of strategies for reducing dispersion in employees' perceptions of diversity climate. First, companies should scrutinize their HR practices and diversity-related events with respect to the signals they send to employees from different demographic subgroups, and should make sure that general HR practices and diversityrelated events are in line (Herdman \& McMillan-Capehart, 2010). Second, organizations should assure that diversity-related practices and procedures are implemented consistently throughout the company by all organizational leaders; for this purpose, supervisors on all levels should be provided with clear guidance and best practices. Third, companies should actively support employees in their sensemaking of diversity-related issues and events by ensuring clear communication. In this regard, managers' diversity-related "actions [...] may not speak as loudly as words; or, better, their words need to match the actions. They may need to actively help their employees interpret what they see by pointing to the policies, practices, and procedures that contributed to creating and sustaining a diverse workforce" (Pugh et al., 2008, p. 1427).

\section{Limitations and Directions for Future Research}

While our study shows several methodological strengths (i.e., use of a large-scale, multi- 
source organizational-level dataset), it also contains some limitations. First, the cross-sectional nature of our data precludes strong causal inference. Although we are confident that our hypotheses are based on sound theoretical reasoning, we cannot entirely rule out the possibility of reversed causality. Such concerns may particularly apply to the link between diversity climate level and collective positive affect, as more positive emotions among employees may lead to generally more favorable perceptions of organizational climate. Therefore, we performed a robustness test to check whether this relationship might be biased by endogeneity (Antonakis, Bendahan, Jacquart, \& Lalive, 2010).

To check for endogeneity, we followed the procedure by Shaver (2005) and specified our core mediation model as a path model with robust standard errors. The model had an acceptable fit $\left(\chi_{2}^{2}=5.32 ; \mathrm{SRMR}=.06 ; \mathrm{CFI}=.96 ; \mathrm{TLI}=.89\right)$. Then we allowed the errors of diversity climate level and collective positive affect to correlate. To keep the model identified, we searched for an instrument that fulfilled the requirement of a direct relationship with diversity climate level, but no direct relationship with collective positive affect (see Shaver, 2005). In our case, we used the diversity climate level of all surveyed companies in the federal state that the target company is located in as an instrument. In this model the error covariance between diversity climate level and collective positive affect was non-significant (Cov=.05; $p=.39)$, and the relationship between diversity climate level and collective positive affect remained positive and significant $(B=.31$; $p=.02$ ). This result suggests a certain robustness of our findings against endogeneity bias. Still, we strongly encourage future studies to replicate our findings using randomized experiments or applying longitudinal research designs.

As a second limitation, our analysis is based on HR executives' subjective assessments of company performance which might raise concerns about the reliability and validity of the measure. In particular, subjective performance ratings might be subject to response biases, such 
as positive impression management (McGrath, Mitchell, Kim, \& Hough, 2010). Yet, the specific nature of our sample precluded the collection of objective performance data for all companies, as the majority of organizations are privately owned SMEs which are not legally obliged to publish annual performance results. As our performance measure significantly correlated with ROE for a sub-sample of companies (see Method section), we are confident that HR executives' subjective performance assessments are valid. Nevertheless, we encourage future research using objective performance measures to replicate the findings from our analysis.

Third, the generalizability of our findings might be limited given the sample of German SMEs. The limited company size might be one reason for the observed range restriction in the diversity climate strength variable, as agreement in climate perceptions among employees might develop more easily in smaller social units. In contrast, lower social proximity in larger social units leaves more room for the development of distinct sub-climates (Colquitt, Noe, \& Jackson, 2002). Hence, the effect of diversity climate strength may be even more pronounced in samples involving larger companies where diversity climate strength scores are less restricted. In a similar vein, we caution readers that the studied companies were all from Germany. It is conceivable that inclusive climates play an even more important role in cultures ranking higher on collectivistic values. Thus, future studies should replicate our findings in other national contexts.

Apart from these limitations, our study offers several avenues for future research. As our findings demonstrate the particular importance of high agreement in employees' climate perceptions, future research may examine how to create such a strong diversity climate. In this regard, the strength of the HRM system may play a pivotal role. A strong HRM system contains process mechanisms that make HR practices distinctive and consistent, and create consensus among employees (Bowen \& Ostroff, 2004). Transferred to the context of diversity climate, it seems plausible that stronger HRM systems help employees in determining the diversity- 
friendliness of their organization.

In addition, as our post hoc analyses provide initial evidence for the relevance of differences in diversity climate appraisals between demographic subgroups, we encourage future research to further substantiate our results by replicating them in a deductive hypothesis testing paradigm (Hollenbeck \& Wright, 2016). Based on these consolidated results, we propose that focusing on patterns, antecedents, and consequences of differences in employees' diversity climate perceptions offers several promising avenues for future investigation. In this regard, researchers may not only look at differences in perceptions along single demographic lines (i.e., men vs. women; old vs. young), but consider various demographic attributes and corresponding diversity climate perceptions simultaneously in a faultline approach (Lau \& Murnighan, 1998) as this might better capture the complexities in real-world organizations.

A more comprehensive understanding of factors determining differences in diversity climate perceptions between demographic subgroups could be gained by examining the role of leadership. Leaders have been argued to act as interpretative filters of organizational events (Luria, 2008) and have been found to influence the emergence of consensus in climate perceptions (González-Romá \& Peiró, 2014). Future research may aim at extending these findings by considering differentiated forms of leadership (e.g., LMX differentiation, differentiated individual-focused transformational leadership) along with leaders' own attitudes toward diversity (Greer et al., 2012) or their subgroup membership (Meyer, Shemla, Li, \& Wegge, 2015) as these factors may lead to systematic variations in the treatment of demographically (dis-)similar followers. As for the consequences of demographic splits in diversity climate perceptions, future multilevel research may also consider individual-level effects, as deviations from dominant diversity climate perceptions may have different implications for members of low and high status groups. 


\section{References}

Agarwal, R., Sarkar, M. B., \& Echambadi, R. (2002). The conditioning effect of time on firm survival: An industry life cycle approach. Academy of Management Journal, 45(5), 971-994.

Anderson, J. C., \& Gerbing, D. W. (1988). Structural equation modeling in practice: A review and recommended two-step approach. Psychological Bulletin, 103(3), 411.

Antonakis, J., Bendahan, S., Jacquart, P., \& Lalive, R. (2010). On making causal claims: A review and recommendations. The Leadership Quarterly, 21(6), 1086-1120.

Ashkanasy, N. M., Härtel, C. E.J., \& Daus, C. S. (2002). Diversity and Emotion: The New Frontiers in Organizational Behavior Research. Journal of Management, 28(3), 307-338.

Avery, D. R., \& McKay, P. F. (2010). Doing diversity right: An empirically based approach to effective diversity management. In G. P. Hodgkinson \& J. K. Ford (Eds.), International Review of Industrial and Organizational Psychology: 2010 (Vol. 25, pp. 227-252). Hoboken: Wiley.

Barrick, M. R., Thurgood, G. R., Smith, T. A., \& Courtright, S. H. (2015). Collective Organizational Engagement: Linking Motivational Antecedents, Strategic Implementation, and Firm Performance. Academy of Management Journal, 58(1), 111-135.

Barsade, S. G. (2002). The Ripple Effect: Emotional Contagion and Its Influence on Group Behavior. Administrative Science Quarterly, 47(4), 644-675.

Barsade, S. G., \& Knight, A. P. (2015). Group Affect. Annual Review of Organizational Psychology and Organizational Behavior, 2(1), 21-46.

Basch, J., \& Fisher, C. D. (2000). Affective events-emotions matrix:: A classification of work events and associated emotions. In N. M. Ashkanasy, C. E. Haertel, \& W. E. Zerbe (Eds.), Emotions in the Workplace: Research, Theory, and Practice (pp. 36-48). Westport, CT: 
Quorum Books/Greenwood Publishing Group.

Baum, J. R., \& Wally, S. (2003). Strategic Decision Speed and Firm Performance. Strategic Management Journal, 24(11), 1107-1129.

Baumeister, R. F., Bratslavsky, E., Finkenauer, C., \& Vohs, K. D. (2001). Bad is stronger than good. Review of General Psychology, 5(4), 323-370.

Becker, T. E. (2005). Potential Problems in the Statistical Control of Variables in Organizational Research: A Qualitative Analysis With Recommendations. Organizational Research Methods, 8(3), 274-289.

Bliese, P. D. (2000). Within group agreement, non-independence, and reliability. In K. J. Klein \& S. W. J. Kozlowski (Eds.), Frontiers of industrial and organizational psychology: 12th bk. Multilevel theory, research, and methods in organizations: Foundations, extensions, and new directions (pp. 349-381). San Francisco: Jossey-Bass.

Boehm, S. A., Dwertmann, D. J. G., Kunze, F., Michaelis, B., Parks, K. M., \& McDonald, D. P. (2014). Expanding Insights on the Diversity Climate-Performance Link: The Role of Workgroup Discrimination and Group Size. Human Resource Management, 53(3), 379-402.

Boehm, S. A., Kunze, F., \& Bruch, H. (2014). Spotlight on Age-Diversity Climate: The Impact of Age-Inclusive HR Practices on Firm-Level Outcomes. Personnel Psychology, 67(3), 667-704.

Bowen, D. E., \& Ostroff, C. (2004). Understanding HRM-firm performance linkages: The role of the "strength" of the HRM system. Academy of Management Review, 29(2), 203-221.

Burke, M. J., Finkelstein, L. M., \& Dusig, M. S. (1999). On Average Deviation Indices for Estimating Interrater Agreement. Organizational Research Methods, 2(1), 49-68.

Chrobot-Mason, D., \& Aramovich, N. P. (2013). The Psychological Benefits of Creating an Affirming Climate for Workplace Diversity. Group \& Organization Management, 38(6), 659- 
689.

Cole, M. S., Bedeian, A. G., Hirschfeld, R. R., \& Vogel, B. (2011). Dispersion-Composition Models in Multilevel Research: A Data-Analytic Framework. Organizational Research Methods, 14(4), 718-734.

Colquitt, J. A., Noe, R. A., \& Jackson, C. L. (2002). Justice in teams: Antecedents and consequences of procedural justice climate. Personnel Psychology, 55(1), 83-109.

Combs, J. G., Crook, T. R., \& Shook, C. L. (2005). The dimensionality of organizational performance and its implications for strategic management research. In D. J. Ketchen \& D. D. Bergh (Eds.), Research methodology in strategy and management (Vol. 2, pp. 259-286). Oxford, UK: Elsevier.

Cox, T. H. J. (1994). Cultural diversity in organizations: Theory, research, \& practice. San Francisco, CA: Berrett-Koehler.

Dawson, J. F., \& Richter, A. W. (2006). Probing three-way interactions in moderated multiple regression: Development and application of a slope difference test. Journal of Applied Psychology, 91(4), 917-926.

De Jong, S. B., Kunze, F., \& Bruch, H. (2017). Organisational consequences of asymmetries in task dependence: The moderating role of HR practices. Human Resource Management Journal, 27(1), 75-93.

Dunlap, W. P., Burke, M. J., \& Smith-Crowe, K. (2003). Accurate tests of statistical significance for r-sub(WG ) and average deviation interrater agreement indexes. Journal of Applied Psychology, 88(2), 356-362.

Dwertmann, D. J. G., Nishii, L. H., \& van Knippenberg, D. (2016). Disentangling the Fairness \& Discrimination and Synergy Perspectives on Diversity Climate. Journal of Management, 
42(5), 1136-1168.

Fredrickson, B. L. (2003). Positive emotions and upward spirals in organizations. In K. S.

Cameron, J. E. Dutton, \& R. E. Quinn (Eds.), Positive organizational scholarship:

Foundations of a new discipline (1st ed., pp. 163-175). San Francisco, CA: Berrett-Koehler.

Ganster, D. C., \& Dwyer, D. J. (1995). The Effects of Understaffing on Individual and Group

Performance in Professional and Trade Occupations. Journal of Management, 21(2), 175-190.

Gardner, R. G., Harris, T. B., Li, N., Kirkman, B. L., \& Mathieu, J. E. (2017). Understanding “It

Depends" in Organizational Research. Organizational Research Methods, 20(4), 610-638.

Gelfand, M. J., Nishii, L. H., Raver, J., \& Schneider, B. (2005). Discrimination in organizations:

An organizational level systems perspective. In R. L. Dipboye \& A. Colella (Eds.), The

organizational frontiers series. Discrimination at work: The psychological and organizational bases (pp. 89-116). Mahwah, N.J.: Lawrence Erlbaum Associates, Publishers.

George, G. (2005). Slack resources and the performance of privately held firms. Academy of Management Journal, 48(4), 661-676.

Gonzalez, J. A., \& DeNisi, A. S. (2009). Cross-level effects of demography and diversity climate on organizational attachment and firm effectiveness. Journal of Organizational Behavior, $30(1), 21-40$.

González-Romá, V., Fortes-Ferreira, L., \& Peiró, J. M. (2009). Team climate, climate strength and team performance. A longitudinal study. Journal of Occupational and Organizational Psychology, 82, 511-536.

González-Romá, V., \& Peiró, J. M. (2014). Climate and Culture Strength. In B. Schneider \& K. M. Barbera (Eds.), The Oxford Handbook of Organizational Climate and Culture (pp. 496531). Oxford, UK: Oxford University Press. 
Greer, L. L., Homan, A. C., De Hoogh, A. H. B., \& Den Hartog, D. N. (2012). Tainted visions: The effect of visionary leader behaviors and leader categorization tendencies on the financial performance of ethnically diverse teams. Journal of Applied Psychology, 97(1), 203-213.

Guillaume, Y. R. F., Dawson, J. F., Otaye-Ebede, L., Woods, S. A., \& West, M. A. (2017). Harnessing demographic differences in organizations: What moderates the effects of workplace diversity? Journal of Organizational Behavior, 38(2), 276-303.

Hage, J., \& Aiken, M. (1967). Relationship of Centralization to Other Structural Properties. Administrative Science Quarterly, 12(1), 72-92.

Harrison, D. A., \& Klein, K. J. (2007). What's the difference? Diversity constructs as separation, variety, or disparity in organizations. Academy of Management Review, 32(4), 1199-1228.

Harrison, D. A., Price, K. H., \& Bell, M. P. (1998). Beyond relational demography: Time and the effects of surface- and deep-level diversity on work group cohesion. Academy of Management Journal, 41(1), 96-107.

Heilman, M. E., \& Eagly, A. H. (2008). Gender Stereotypes Are Alive, Well, and Busy Producing Workplace Discrimination. Industrial and Organizational Psychology, 1(04), 393398.

Herdman, A. O., \& McMillan-Capehart, A. (2010). Establishing a Diversity Program is Not Enough: Exploring the Determinants of Diversity Climate. Journal of Business and Psychology, 25(1), 39-53.

Hmieleski, K. M., Cole, M. S., \& Baron, R. A. (2012). Shared Authentic Leadership and New Venture Performance. Journal of Management, 38(5), 1476-1499.

Hogg, M. A., \& Terry, D. I. (2000). Social Identity and Self-Categorization Processes in Organizational Contexts. Academy of Management Review, 25(1), 121-140. 
Hu, L.-t., \& Bentler, P. M. (1999). Cutoff criteria for fit indexes in covariance structure analysis: Conventional criteria versus new alternatives. Structural Equation Modeling: A Multidisciplinary Journal, 6(1), 1-55.

Jackson, S. E., \& Joshi, A. (2011). Work team diversity. In S. Zedeck (Ed.), APA handbook of industrial and organizational psychology: Vol. 1. Building and developing the organization (pp. 651-686). Washington, D.C.: American Psychological Association.

James, L. R., Demaree, R. G., \& Wolf, G. (1984). Estimating within-group interrater reliability with and without response bias. Journal of Applied Psychology, 69(1), 85-98.

Jetten, J., Haslam, S. A., \& Haslam, C. (2012). The case for social identity analysis of health and well-being. In J. Jetten, C. Haslam, \& S. A. Haslam (Eds.), The social cure: Identity, health and well-being (pp. 3-19). Hove, New York: Psychology Press.

Johnson, P. O., \& Neyman, J. (1936). Tests of certain linear hypotheses and their application to some educational problems. Statistical Research Memoirs, 1, 57-93.

Joshi, A., \& Roh, H. (2009). The role of context in work team diversity research: A meta-analytic review. Academy of Management Journal, 52(3), 599-627.

Knight, A. P., Menges, J. I., \& Bruch, H. (2018). Organizational Affective Tone: A Meso Perspective on the Origins and Effects of Consistent Affect in Organizations. Academy of Management Journal, 61(1), 191-219.

Kopelman, R. E., Brief, A. P., \& Guzzo, R. A. (1990). The role of climate and culture in productivity. In B. Schneider (Ed.), A Joint publication in the Jossey-Bass management series and the Jossey-Bass social and behavioral science series. Organizational climate and culture (1st ed., pp. 282-318). San Francisco: Jossey-Bass.

Kossek, E. E., \& Zonia, S. C. (1993). Assessing Diversity Climate: A Field Study of Reactions to 
Employer Efforts to Promote Diversity. Journal of Organizational Behavior, 14(1), 61-81.

Kuenzi, M., \& Schminke, M. (2009). Assembling Fragments Into a Lens: A Review, Critique, and Proposed Research Agenda for the Organizational Work Climate Literature. Journal of Management, 35(3), 634-717.

Kunze, F., Raes, A. M. L., \& Bruch, H. (2015). It matters how old you feel: Antecedents and performance consequences of average relative subjective age in organizations. Journal of Applied Psychology, 100(5), 1511-1526.

Labianca, G., \& Brass, D. J. (2006). Exploring the Social Ledger: Negative Relationships and Negative Asymmetry in Social Networks in Organizations. Academy of Management Review, $31(3), 596-614$.

Lau, D. C., \& Murnighan, J. K. (1998). Demographic diversity and faultlines: The compositional dynamics of organizational groups. Academy of Management Review, 23(2), 325-340.

LeBreton, J. M., \& Senter, J. L. (2008). Answers to 20 Questions About Interrater Reliability and Interrater Agreement. Organizational Research Methods, 11(4), 815-852.

Luria, G. (2008). Climate strength-How leaders form consensus. The Leadership Quarterly, 19(1), 42-53.

Marsh, H. W., Hau, K.-T., \& Wen, Z. (2004). In Search of Golden Rules: Comment on Hypothesis-Testing Approaches to Setting Cutoff Values for Fit Indexes and Dangers in Overgeneralizing Hu and Bentler's (1999) Findings. Structural Equation Modeling: A Multidisciplinary Journal, 11(3), 320-341.

McGrath, R. E., Mitchell, M., Kim, B. H., \& Hough, L. (2010). Evidence for response bias as a source of error variance in applied assessment. Psychological Bulletin, 136(3), 450-470.

McKay, P. F., \& Avery, D. R. (2006). What has race got to do with it? Unraveling the role of 
racioethnicity in job seekers' reactions to site visits. Personnel Psychology, 59(2), 395-429.

McKay, P. F., \& Avery, D. R. (2015). Diversity Climate in Organizations: Current Wisdom and Domains of Uncertainty. In A. R. Wheeler \& Halbesleben, J. R. B. (Eds.), Research in personnel and human resources management (pp. 191-233). Bingley, UK: Emerald Group. McKay, P. F., Avery, D. R., Liao, H., \& Morris, M. A. (2011). Does Diversity Climate Lead to Customer Satisfaction? It Depends on the Service Climate and Business Unit Demography. Organization Science, 22(3), 788-803.

McKay, P. F., Avery, D. R., \& Morris, M. A. (2008). Mean racial-ethnic differences in employee sales performance: The moderating role of diversity climate. Personnel Psychology, 61(2), 349-374.

Menges, J. I., \& Kilduff, M. (2015). Group Emotions: Cutting the Gordian Knots Concerning Terms, Levels of Analysis, and Processes. Academy of Management Annals, 9(1), 845-928.

Menges, J. I., Walter, F., Vogel, B., \& Bruch, H. (2011). Transformational leadership climate: Performance linkages, mechanisms, and boundary conditions at the organizational level. The Leadership Quarterly, 22(5), 893-909.

Meyer, B., Shemla, M., Li, J., \& Wegge, J. (2015). On the Same Side of the Faultline: Inclusion in the Leader's Subgroup and Employee Performance. Journal of Management Studies, 52(3), $354-380$.

Meyers, L. S., Gamst, G., \& Guarino, A. J. (2006). Applied multivariate research: Design and interpretation. Thousand Oaks: Sage Publications.

Mischel, W. (1976). Towards a cognitive social model learning reconceptualization of personality. In N. S. Endler \& D. Magnusson (Eds.), The series in clinical and community psychology. Interactional psychology and personality (pp. 166-207). New York: Wiley. 
Morgeson, F. P., \& Hofmann, D. A. (1999). The Structure and Function of Collective Constructs: Implications for Multilevel Research and Theory Development. Academy of Management Review, 24(2), 249-265.

Ng, T. W. H., \& Feldman, D. C. (2008). The relationship of age to ten dimensions of job performance. Journal of Applied Psychology, 93(2), 392-423.

O’Brien, R. M. (2007). A Caution Regarding Rules of Thumb for Variance Inflation Factors. Quality \& Quantity, 41(5), 673-690.

Orlitzky, M. (2001). Does firm size comfound the relationship between corporate social performance and firm financial performance? Journal of Business Ethics, 33(2), 167-180.

Parke, M. R., \& Seo, M.-G. (2017). The Role of Affect Climate in Organizational Effectiveness. Academy of Management Review, 42(2), 334-360.

Pierce, J. L., \& Gardner, D. G. (2004). Self-Esteem Within the Work and Organizational Context: A Review of the Organization-Based Self-Esteem Literature. Journal of Management, 30(5), $591-622$.

Posthuma, R. A., \& Campion, M. A. (2009). Age Stereotypes in the Workplace: Common Stereotypes, Moderators, and Future Research Directions $\dagger$. Journal of Management, 35(1), $158-188$.

Preacher, K. J., Rucker, D. D., \& Hayes, A. F. (2007). Addressing Moderated Mediation Hypotheses: Theory, Methods, and Prescriptions. Multivariate Behavioral Research, 42(1), $185-227$.

Pugh, S. D., Dietz, J., Brief, A. P., \& Wiley, J. W. (2008). Looking inside and out: The impact of employee and community demographic composition on organizational diversity climate. Journal of Applied Psychology, 93(6), 1422-1428. 
Rimé, B. (2009). Emotion Elicits the Social Sharing of Emotion: Theory and Empirical Review. Emotion Review, 1(1), 60-85.

Roberson, Q. M., Sturman, M. C., \& Simons, T. L. (2007). Does the Measure of Dispersion Matter in Multilevel Research? A Comparison of the Relative Performance of Dispersion Indexes. Organizational Research Methods, 10(4), 564-588.

Schminke, M., Cropanzano, R., \& Rupp, D. E. (2002). Organization structure and fairness perceptions: The moderating effects of organizational level. Organizational Behavior and Human Decision Processes, 89(1), 881-905.

Schneider, B., Ehrhart, M. G., \& Macey, W. H. (2013). Organizational climate and culture. Annual Review of Psychology, 64, 361-388.

Schwarz, N., \& Clore, G. L. (2003). Mood as Information: 20 Years Later. Psychological Inquiry, 14(3-4), 296-303.

Shaver, J. M. (2005). Testing for Mediating Variables in Management Research: Concerns, Implications, and Alternative Strategies. Journal of Management, 31(3), 330-353.

Singh, S., Darwish, T. K., \& Potočnik, K. (2016). Measuring organizational performance: A case for subjective measures. British Journal of Management, 27(1), 214-224.

Soellner, R. (2014). Die wirtschaftliche Bedeutung kleiner und mittlerer Unternehmen in Deutschland. (The economic impact of small- and medium-sized enterprises in Germany). Wiesbaden, Germany: German Federal Statistical Office.

Tabachnick, B. G., \& Fidell, L. S. (2013). Using multivariate statistics (6th ed.). Harlow, UK: Pearson Longman.

Tsai, W.-C., Chen, C.-C., \& Liu, H.-L. (2007). Test of a model linking employee positive moods and task performance. Journal of Applied Psychology, 92(6), 1570-1583. 
van Katwyk, P. T., Fox, S., Spector, P. E., \& Kelloway, E. K. (2000). Using the Job-Related Affective Well-Being Scale (JAWS) to investigate affective responses to work stressors. Journal of Occupational Health Psychology, 5(2), 219-230.

van Knippenberg, D., \& Schippers, M. C. (2007). Work group diversity. Annual Review of Psychology, 58, 515-541.

Venkatraman, N., \& Ramanujam, V. (1986). Measurement of Business Performance in Strategy Research: A Comparison of Approaches. Academy of Management Review, 11(4), 801-814.

Walter, F., \& Bruch, H. (2010). Structural impacts on the occurrence and effectiveness of transformational leadership: An empirical study at the organizational level of analysis. The Leadership Quarterly, 21(5), 765-782.

Weiss, H. M., \& Cropanzano, R. (1996). Affective events theory: A theoretical discussion of the structure, causes and consequences of affective experiences at work. In B. M. Staw \& L. L. Cummings (Eds.), Research in organizational behavior: An annual series of analytical essays and critical reviews (Vol. 18, pp. 1-74). Greenwich, CT: Jai Press.

Welter, F., May-Strobl, E., Holz, M., Pahnke, A., Schlepphorst, S., \& Wolter, H.-J. (2014). German Mittelstand - Between Facts and Perceptions. Bonn, Germany: German Institute for Research on Small- and Medium-Sized Companies.

Zahra, S. A., Ireland, R. D., \& Hitt, M. A. (2000). International expansion by new venture firms: International diversity, mode of market entry, technological learning, and performance. Academy of Management Journal, 43(5), 925-950.

Zohar, D. (2000). A group-level model of safety climate: Testing the effect of group climate on microaccidents in manufacturing jobs. Journal of Applied Psychology, 85(4), 587-596.

Zohar, D., \& Luria, G. (2004). Climate as a social-cognitive construction of supervisory safety 
practices: Scripts as proxy of behavior patterns. Journal of Applied Psychology, 89(2), 322333. 


\section{Table 1}

Descriptive Statistics and Organizational-level Correlations

\begin{tabular}{|c|c|c|c|c|c|c|c|c|c|c|c|c|c|c|c|c|}
\hline Variable & $\mathbf{M}$ & SD & 1 & 2 & 3 & 4 & 5 & 6 & 7 & 8 & 9 & 10 & 11 & 12 & 13 & 14 \\
\hline $\begin{array}{l}1 \text { Diversity Climate } \\
\text { Level }\end{array}$ & 5.24 & .64 & & & & & & & & & & & & & & \\
\hline $\begin{array}{l}2 \text { Diversity Climate } \\
\text { Strength }\end{array}$ & -1.00 & .24 & $.70 *$ & & & & & & & & & & & & & \\
\hline 3 Age Diversity & 10.75 & 2.00 & $-.26 *$ & -.19 & & & & & & & & & & & & \\
\hline 4 Gender Diversity & .40 & .11 & .07 & .01 & -.02 & & & & & & & & & & & \\
\hline $\begin{array}{l}5 \text { Collective Positive } \\
\text { Affect }\end{array}$ & 3.31 & .39 & $.71 * *$ & $.50 * *$ & $-.28 * *$ & -.01 & & & & & & & & & & \\
\hline $\begin{array}{l}6 \text { Company } \\
\text { Performance }\end{array}$ & 3.87 & .75 & $.42 * *$ & .22 & $-.23 *$ & .13 & $.46 * *$ & & & & & & & & & \\
\hline 7 Company Size & 380.99 & 577.14 & $-.24 *$ & $-.24 *$ & .15 & .01 & $-.35 * *$ & -.19 & & & & & & & & \\
\hline 8 Company Age & 49.17 & 45.13 & $-.24 *$ & -.18 & $.37 * *$ & -.09 & $-.30 * *$ & $-.27 *$ & $.22 *$ & & & & & & & \\
\hline 9 Centralization & 3.23 & .74 & $-.67 * *$ & $-.47 * *$ & .20 & -.05 & $-.53 * *$ & -.12 & $.26 *$ & .13 & & & & & & \\
\hline 10 Coworker Support & 3.97 & .30 & $.67 * *$ & $.39 * *$ & -.16 & .02 & $.67 * *$ & $.25 *$ & $-.24 *$ & -.17 & $-.53 * *$ & & & & & \\
\hline 11 Slack Resources & 5.70 & 1.22 & .15 & -.11 & .06 & .07 & .12 & $.41 * *$ & .05 & -.18 & -.19 & .18 & & & & \\
\hline 12 Staffing & 2.65 & .71 & -.10 & .11 & $.32 * *$ & -.08 & -.06 & $-.28 *$ & .15 & .06 & .16 & .14 & -.13 & & & \\
\hline 13 Production & .35 & .48 & $-.32 * *$ & $-.27 *$ & $.25 *$ & -.04 & $-.46 * *$ & -.12 & .10 & $.32 * *$ & .19 & $-.34 * *$ & -.05 & -.03 & & \\
\hline 14 Trade & .20 & .41 & -.04 & -.06 & .20 & .02 & .01 & -.04 & -.14 & -.03 & .09 & .05 & .10 & .09 & $-.32 * *$ & \\
\hline 15 Service & .40 & .49 & $.28 *$ & $.23 *$ & $-.39 * *$ & -.06 & $.33 * *$ & .16 & -.01 & $-.34 * *$ & -.20 & $.27 *$ & -.05 & -.10 & $-.54 * *$ & $-.35 * *$ \\
\hline
\end{tabular}




\section{Table 2}

Regression Models Involving Diversity Climate Strength and Demographic Diversity as Moderators

\begin{tabular}{|c|c|c|c|c|c|c|c|c|c|c|c|c|c|c|c|}
\hline \multirow[b]{2}{*}{ Varible } & \multicolumn{3}{|c|}{ Step 1} & \multicolumn{3}{|c|}{ Step 2} & \multicolumn{3}{|c|}{ Step 3} & \multicolumn{3}{|c|}{ Step 4} & \multicolumn{3}{|c|}{ Step 5} \\
\hline & $\boldsymbol{B}$ & $S E$ & $p$ & $\boldsymbol{B}$ & $S E$ & $p$ & $\boldsymbol{B}$ & $S E$ & $p$ & $B$ & $S E$ & $p$ & $B$ & $S E$ & $p$ \\
\hline Company Size (log) & -.05 & $(.03)$ & .14 & -.05 & $(.03)$ & .12 & -.03 & $(.03)$ & .29 & -.03 & $(.03)$ & .31 & -.03 & $(.03)$ & .34 \\
\hline Company Age & .00 & $(.00)$ & .43 & .00 & $(.00)$ & .62 & .00 & $(.00)$ & .54 & .00 & $(.00)$ & .52 & .00 & $(.00)$ & .56 \\
\hline Staffing Sufficiency & -.04 & $(.05)$ & .39 & -.03 & $(.05)$ & .62 & -.05 & $(.05)$ & .38 & -.03 & $(.05)$ & .51 & -.04 & $(.05)$ & .47 \\
\hline Slack Resources & -.01 & $(.02)$ & .80 & .00 & $(.02)$ & .96 & -.01 & $(.02)$ & .65 & .01 & $(.02)$ & .62 & .00 & $(.02)$ & .95 \\
\hline Centralization & -.09 & $(.06)$ & .13 & -.01 & $(.05)$ & .89 & -.04 & $(.06)$ & .44 & -.03 & $(.08)$ & .66 & -.05 & $(.06)$ & .43 \\
\hline Coworker Support & .61 & $(.14)$ & .00 & .40 & $(.14)$ & .01 & .41 & $(.13)$ & .00 & .39 & $(.13)$ & .00 & .41 & $(.14)$ & .00 \\
\hline Production Sector & -.27 & $(.07)$ & .00 & -.24 & $(.06)$ & .00 & -.27 & $(.06)$ & .00 & -.28 & $(.07)$ & .00 & -.26 & $(.06)$ & .00 \\
\hline Trade Sector & -.14 & $(.10)$ & .15 & -.13 & $(.09)$ & .15 & -.16 & $(.08)$ & .05 & -.15 & $(.08)$ & .07 & -.16 & $(.09)$ & .07 \\
\hline Service Sector & -.08 & $(.07)$ & .26 & -.08 & $(.06)$ & .19 & -.10 & $(.06)$ & .11 & -.12 & $(.07)$ & .08 & -.08 & $(.07)$ & .24 \\
\hline Diversity Climate Level (DCL) & & & & .23 & $(.10)$ & .03 & .20 & $(.10)$ & .05 & .14 & $(.10)$ & .18 & .17 & $(.11)$ & .12 \\
\hline Diversity Climate Strength (DCS) & & & & -.01 & $(.18)$ & .95 & -.06 & $(.18)$ & .71 & .12 & $(.21)$ & .59 & -.01 & $(.16)$ & .94 \\
\hline Age Diversity (AD) & & & & .00 & $(.02)$ & .92 & .00 & $(.02)$ & .81 & .02 & $(.02)$ & .46 & .01 & $(.02)$ & .75 \\
\hline Gender Diversity (GD) & & & & -.25 & $(.27)$ & .36 & -.33 & $(.26)$ & .21 & -.40 & $(.28)$ & .15 & -.44 & $(.32)$ & .17 \\
\hline DCL x DCS & & & & & & & .27 & $(.13)$ & .04 & .22 & $(.14)$ & .12 & .21 & $(.12)$ & .08 \\
\hline DCL x AD & & & & & & & & & & -.06 & $(.02)$ & .01 & & & \\
\hline $\mathrm{DCS} \times \mathrm{AD}$ & & & & & & & & & & .13 & $(.05)$ & .01 & & & \\
\hline DCL $x$ DCS x AD & & & & & & & & & & -.05 & $(.05)$ & .34 & & & \\
\hline DCL x GD & & & & & & & & & & & & & -.59 & $(.39)$ & .14 \\
\hline DCS x GD & & & & & & & & & & & & & 2.67 & (1.18) & .03 \\
\hline DCL x DCS x GD & & & & & & & & & & & & & .93 & (1.23) & .45 \\
\hline Constant & 1.77 & $(.63)$ & .01 & 2.24 & $(.60)$ & .00 & 2.37 & $(.59)$ & .00 & 2.26 & $(.60)$ & .00 & 2.27 & $(.61)$ & .00 \\
\hline$R^{2}$ & .61 & & .00 & .66 & & .00 & .68 & & .00 & .71 & & .00 & .69 & & .00 \\
\hline$\Delta R^{2} F$ test & & & & .06 & & .03 & .02 & & .04 & .03 & & .01 & .01 & & .10 \\
\hline
\end{tabular}

$N=82$. Regression models report unstandardized estimates. Robust standard errors in parentheses. 


\section{Table 3}

Regression Model Involving Collective Positive Affect and Company Performance

\begin{tabular}{|c|c|c|c|c|c|c|c|c|c|}
\hline \multirow[b]{2}{*}{ Varible } & \multicolumn{3}{|c|}{ Step 1} & \multicolumn{3}{|c|}{ Step 2} & \multicolumn{3}{|c|}{ Step 3} \\
\hline & $B$ & $S E$ & $p$ & $B$ & $S E$ & $p$ & $B$ & $S E$ & $p$ \\
\hline Company Size (log) & -.09 & $(.06)$ & .13 & -.10 & $(.06)$ & .10 & -.06 & $(.06)$ & .31 \\
\hline Company Age & .00 & $(.00)$ & .52 & .00 & $(.00)$ & .83 & .00 & $(.00)$ & .99 \\
\hline Staffing Sufficiency & -.23 & $(.12)$ & .05 & -.18 & $(.10)$ & .06 & -.16 & $(.09)$ & .08 \\
\hline Slack Resources & .23 & $(.08)$ & .00 & .24 & $(.07)$ & .00 & .24 & $(.07)$ & .00 \\
\hline Centralization & .22 & $(.12)$ & .08 & .45 & $(.11)$ & .00 & .46 & $(.11)$ & .00 \\
\hline Coworker Support & .61 & $(.29)$ & .04 & .00 & $(.28)$ & 1.00 & -.33 & $(.28)$ & .25 \\
\hline Production Sector & .00 & (.19) & .99 & .09 & (.17) & .60 & .29 & (.17) & .09 \\
\hline Trade Sector & -.16 & $(.23)$ & .50 & -.10 & $(.19)$ & .60 & .00 & $(.17)$ & 1.00 \\
\hline Service Sector & .06 & $(.17)$ & .73 & .10 & $(.17)$ & .57 & .16 & (.16) & .31 \\
\hline Age Diversity & -.04 & (.04) & .34 & -.03 & $(.03)$ & .36 & -.03 & $(.03)$ & .39 \\
\hline Gender Diversity & .62 & (.66) & .35 & .56 & (.64) & .38 & .76 & $(.55)$ & .17 \\
\hline Diversity Climate Level & & & & .68 & $(.16)$ & .00 & .49 & $(.17)$ & .01 \\
\hline Collective Positive Affect & & & & & & & .82 & $(.24)$ & .00 \\
\hline Constant & .58 & $(1.55)$ & .71 & 1.98 & $(1.35)$ & .15 & .15 & $(1.47)$ & .92 \\
\hline$R^{2}$ & .35 & & .00 & .48 & & .00 & .54 & & .00 \\
\hline$\Delta R^{2} F$ test & & & & .13 & & .00 & .06 & & .00 \\
\hline
\end{tabular}


Table 4

Regression Models Involving Diversity Climate Strength and Convergence in Diversity Climate Perceptions between Demographic Subgroups as Moderators

\begin{tabular}{|c|c|c|c|c|c|c|}
\hline \multirow[b]{2}{*}{ Varible } & \multicolumn{3}{|c|}{ Step 1} & \multicolumn{3}{|c|}{ Step 2} \\
\hline & $B$ & $\begin{array}{l}S E \\
\end{array}$ & $p$ & $B$ & $S E$ & $p$ \\
\hline Age Diversity & .02 & $(.02)$ & .29 & .02 & $(.02)$ & .41 \\
\hline Gender Diversity & -.22 & $(.28)$ & .44 & -.10 & $(.27)$ & .73 \\
\hline Company Size (log) & -.01 & $(.03)$ & .66 & .00 & $(.04)$ & .99 \\
\hline Company Age & .00 & $(.00)$ & .02 & .00 & $(.00)$ & .03 \\
\hline Staffing Sufficiency & -.06 & $(.06)$ & .28 & -.05 & $(.06)$ & .41 \\
\hline Slack Resources & .01 & (.03) & .74 & .00 & (.03) & .92 \\
\hline Centralization & -.09 & $(.09)$ & .29 & -.06 & $(.08)$ & .47 \\
\hline Coworker Support & .45 & (.13) & .00 & .43 & (.14) & .00 \\
\hline Production Sector & -.34 & $(.07)$ & .00 & -.25 & $(.07)$ & .00 \\
\hline Trade Sector & -.26 & $(.08)$ & .00 & -.20 & (.08) & .02 \\
\hline Service Sector & -.16 & $(.06)$ & .02 & -.09 & $(.07)$ & .20 \\
\hline Diversity Climate Level(DCL) & .11 & (.11) & .36 & .08 & (.13) & .53 \\
\hline Diversity Climate Strength (DCS) & -.32 & $(.23)$ & .17 & .03 & $(.25)$ & .91 \\
\hline $\begin{array}{l}\text { Age-related Convergence in Diversity Climate } \\
\text { Perceptions (ACDCP) }\end{array}$ & -.07 & $(.09)$ & .49 & -.01 & $(.08)$ & .95 \\
\hline $\begin{array}{l}\text { Gender-related Convergence in Diversity Climate } \\
\text { Perceptions (GCDCP) }\end{array}$ & .08 & (.10) & .44 & .02 & (.11) & .86 \\
\hline DCL $x$ DCS & .34 & (.17) & .05 & .33 & (.18) & .07 \\
\hline DCL $x$ ACDCP & .41 & (.19) & .04 & & & \\
\hline DCS x ACDCP & -.63 & $(.56)$ & .26 & & & \\
\hline DCL $x$ DCS $x$ ACDCP & .75 & $(.27)$ & .01 & & & \\
\hline DCL x GCDCP & & & & .07 & (.12) & .58 \\
\hline DCS x GCDCP & & & & .43 & (.37) & .26 \\
\hline DCL $x$ DCS $x$ GCDCP & & & & .71 & (.36) & .05 \\
\hline Constant & 2.27 & $(.54)$ & .00 & 2.10 & $(.58)$ & .00 \\
\hline$R^{2}$ & .75 & & .00 & .73 & & .00 \\
\hline
\end{tabular}

$N=76$. Regression models report unstandardized estimates. Robust standard errors in parentheses. 


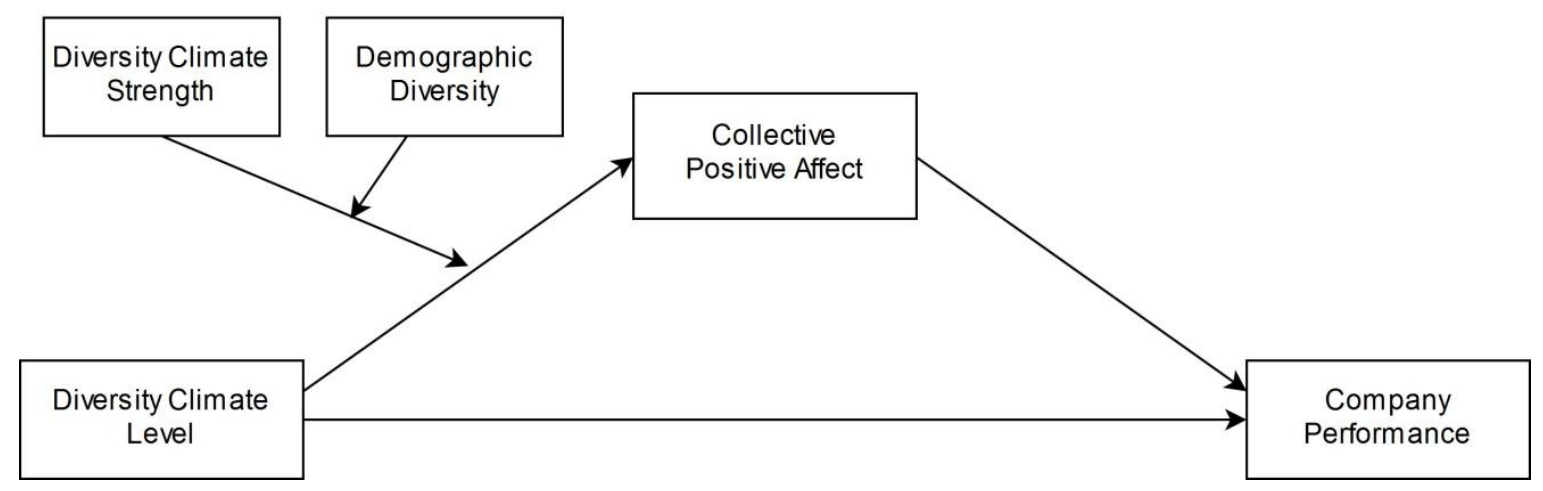

Figure 1. Overview of conceptual model.

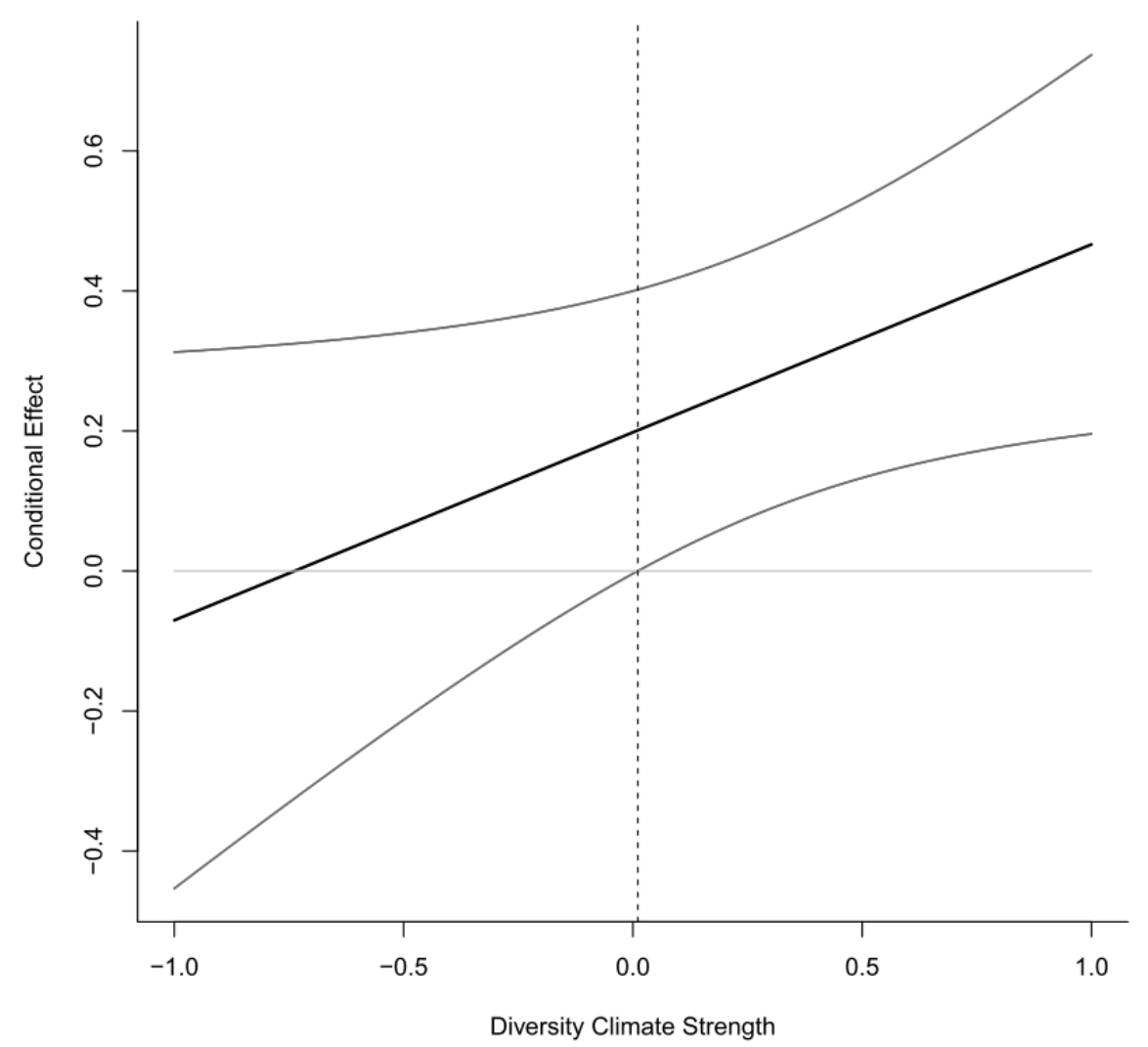

Figure 2. Johnson-Neyman regions of significance for the conditional relation between diversity climate level and collective positive affect at values of diversity climate strength. The black line depicts the conditional effect of diversity climate level on collective positive affect ( $y$ axis) dependent on the value of the diversity climate strength moderator ( $x$ axis). The curved 
grey lines represent the $95 \%$ confidence intervals around the conditional effect. The points at which the confidence interval does not include zero depict the region of significance of the conditional effect.
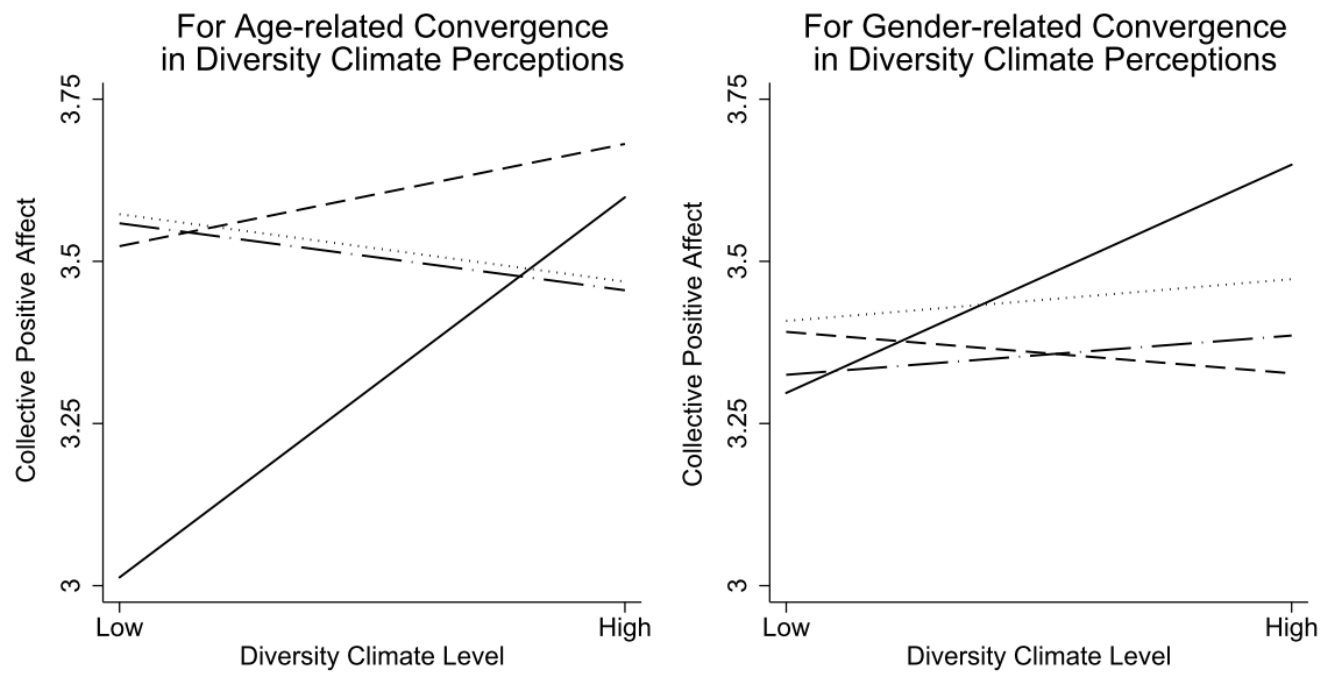

Low Climate Strength \& Low Convergence

- - - - - Low Climate Strength \& High Convergence

- - - High Climate Strength \& Low Convergence

High Climate Strength \& High Convergence

Figure 3. Interaction of diversity climate level with diversity climate strength and convergence in diversity climate perceptions between demographic subgroups on collective positive affect. 


\section{Appendix}

\begin{tabular}{|c|c|c|c|}
\hline Construct & Items & Scale & Source \\
\hline $\begin{array}{l}\text { Diversity } \\
\text { Climate }\end{array}$ & $\begin{array}{l}\text { 1. My company maintains a diversity- } \\
\text { friendly work environment. } \\
\text { 2. My company respects the views of people } \\
\text { like me. } \\
\text { 3. I trust my company to treat me fairly. } \\
\text { 4. The top leaders in my company } \\
\text { demonstrate a visible commitment to } \\
\text { diversity. }\end{array}$ & $\begin{array}{l}\text { 7-point } \\
(1=\text { strongly } \\
\text { disagree, } \\
7=\text { strongly } \\
\text { agree })\end{array}$ & $\begin{array}{l}\text { McKay et al. } \\
(2008)\end{array}$ \\
\hline $\begin{array}{l}\text { Collective } \\
\text { Positive Affect }\end{array}$ & $\begin{array}{l}\text { The employees of our company... } \\
\text { 1. ... are enthused by their work. } \\
\text { 2. ...feel that their work is inspiring. } \\
\text { 3. ...feel that their work is exciting. } \\
\text { 4. ... feel full of energy at work. } \\
\text { 5. .... are euphoric at work. }\end{array}$ & $\begin{array}{c}\text { 5-point } \\
(1=\text { never, } \\
\text { 5=very } \\
\text { often/always })\end{array}$ & $\begin{array}{l}\text { Knight \& } \\
\text { Menges } \\
(2018)\end{array}$ \\
\hline $\begin{array}{l}\text { Organizational } \\
\text { Performance }\end{array}$ & $\begin{array}{l}\text { Please rate the performance of your company } \\
\text { compared to that of your direct industry } \\
\text { competitors with regard to the following } \\
\text { criteria: } \\
\text { 1. Overall company performance. } \\
\text { 2. Efficiency of business processes. } \\
\text { 3. Increase in market share. }\end{array}$ & $\begin{array}{l}\text { 5-point } \\
(1=\text { far below } \\
\text { average, } \\
5=\text { far above } \\
\text { average })\end{array}$ & $\begin{array}{l}\text { Combs et al. } \\
(2005)\end{array}$ \\
\hline Centralization & $\begin{array}{l}\text { 1. Even for small things employees have to } \\
\text { get the permission from a supervisor } \\
\text { before they can make a final decision. } \\
\text { 2. Employees must almost always ask their } \\
\text { supervisor for what they should be doing. } \\
\text { 3. For most decisions employees make, the } \\
\text { supervisor needs to give approval. }\end{array}$ & $\begin{array}{l}\text { 7-point } \\
(1=\text { strongly } \\
\text { disagree, } \\
5=\text { strongly } \\
\text { agree })\end{array}$ & $\begin{array}{l}\text { Hage \& Aiken } \\
\text { (1967) }\end{array}$ \\
\hline $\begin{array}{l}\text { Coworker } \\
\text { Support }\end{array}$ & $\begin{array}{l}\text { To what extent... } \\
\text { 1. ...do you get the resources you need for } \\
\text { your job from your coworkers? } \\
\text { 2. ...do you get the advice you need for your } \\
\text { job from your coworkers? }\end{array}$ & $\begin{array}{c}\text { 5-point } \\
(1=\text { not at all, } \\
\begin{array}{c}5=\text { to a great } \\
\text { extent })\end{array}\end{array}$ & $\begin{array}{l}\text { Jetten et al. } \\
(2012)\end{array}$ \\
\hline
\end{tabular}

